\title{
Evaluation of Aeolus L2B wind product with wind profiling radar measurements and numerical weather prediction model equivalents over Australia
}

Haichen Zuo ${ }^{1}$, Charlotte Bay Hasager ${ }^{1}$, Ioanna Karagali², Ad Stoffelen ${ }^{3}$, Gert-Jan Marseille ${ }^{3}$, Jos de Kloe ${ }^{3}$

$5 \quad{ }^{1}$ Wind Energy, Technical University of Denmark, Roskilde, 4000, Denmark

${ }^{2}$ Danish Meteorological Institute, Copenhagen, 2100, Denmark

${ }^{3}$ Royal Netherlands Meteorological Institute, De Bilt, 3731 GA, Netherlands

Correspondence to: Haichen Zuo (hazu@dtu.dk)

10 Abstract. Carrying a laser Doppler instrument, the Aeolus satellite was launched in 2018, becoming the first mission for atmospheric wind profile measurements from space. Before utilizing the Aeolus winds for different applications, evaluating its data quality is essential. With the help of ground-based wind profiling radar measurements and the European Centre for Medium-Range Weather Forecasts (ECMWF) model equivalents, this study quantifies the error characteristics of Aeolus L2B (baseline-11) near real time horizontal line-of-sight winds across Australia by using both inter-comparison and triple

15 collocation analysis. The results of the inter-comparison analysis indicate that both Rayleigh-clear winds and Mie-cloudy winds are in good agreement with the ground-based radar measurements with overall absolute mean biases smaller than $0.7 \mathrm{~m}$ $\mathrm{s}^{-1}$ and correlation coefficients larger than 0.9. Moreover, taking radar measurements as reference data set, Mie-cloudy winds are shown to be more precise than Rayleigh-clear winds with an overall random error of $5.81 \mathrm{~m} \mathrm{~s}^{-1}$ for Rayleigh-clear winds and $4.14 \mathrm{~m} \mathrm{~s}^{-1}$ for Mie-cloudy winds. Similar results were also found from triple collocation analysis, with error standard deviations of $5.61 \mathrm{~m} \mathrm{~s}^{-1}$ and $3.50 \mathrm{~m} \mathrm{~s}^{-1}$ for Rayleigh-clear winds and Mie-cloudy winds, respectively. In addition, the Mie channel is shown to be better capable of capturing the wind in the planetary boundary layer $(<1,500 \mathrm{~m})$. The findings of this study demonstrate the good performance of space-borne Doppler lidar for wind profiling and provide valuable information for data assimilation in numerical weather prediction.

\section{Introduction}

25 The lack of wind profiles still is one of the major deficiencies in the Global Observing System (GOS), which limits our knowledge of atmospheric dynamics and the performance of numerical weather prediction (NWP) (World Meteorological Organization (WMO), 2004). To help close this gap, after more than 15 years of design, the Aeolus satellite carrying an Atmospheric Laser Doppler Instrument (ALADIN) was launched by the European Space Agency (ESA) in 2018, becoming the first satellite mission in the world for measuring wind profiles from space. 
After a successful launch, Aeolus is in a sun-synchronous orbit with a 7-day repeat cycle. It crosses the equator at 18:00 LT (Local time) during ascending orbits (from south to north) and at 06:00 LT during descending orbits (from north to south). The azimuth angle of Aeolus is $\sim 260^{\circ}$ for ascending orbits and $\sim 100^{\circ}$ for descending orbits, away from the poles. The viewing angle of ALADIN toward the atmosphere is $35^{\circ}$ off-nadir. The measured wind along the laser beam line-of-sight (LOS) is then converted to the horizontal to give the horizontal line-of-sight (HLOS) wind component, which is approximately east-west oriented for most of the orbits. Wind retrievals of ALADIN are based on light scattering by atmospheric molecules and particulates (aerosol, cloud droplets, and ice crystals) which move with the ambient wind and the Doppler effect (Ingmann and Straume, 2016). The laser system of ALADIN emits a beam of powerful light in the ultraviolet part of the electromagnetic spectrum at $355 \mathrm{~nm}$ towards the Earth. Then, the backscattered light from the atmosphere is collected by the telescope and

40 transferred to the receiver for analysis. Since the laser light can be backscattered by both molecules and particulates in the atmosphere, ALADIN has two separate detection channels. One is for Rayleigh scattering from molecules, such as oxygen and nitrogen, with the diameter being about 0.3-0.4 nm that is smaller than the light wavelength; the other is for Mie scattering from the large particles such as cloud droplets and ice crystals, dust, and aerosols, the diameters of which are usually greater than $1 \mu \mathrm{m}$ (Calvert, 1990; Wallace and Hobbs, 2006; Ingmann and Straume, 2016; Vallejos-Burgos et al., 2018). From the backscattered signal, winds from the surface to about $30 \mathrm{~km}$ in height can be derived, depending on the range bin settings, i.e., the size of the 24 bins defining the wind profile.

By detecting worldwide wind profiles from space, the Aeolus satellite has the potential to serve a variety of applications, including further exploring atmospheric dynamics, improving numerical weather predictions, and better estimating the 50 dispersion of air pollutants (Banyard et al., 2021; ESA, 2021; Rennie et al., 2021). However, before employing Aeolus winds for different applications, it is essential to know the error characteristics of the wind products. In-situ measurements (e.g. radiosondes), ground-based remote sensing observations (e.g. lidar or radar) and NWP model equivalents are the three main reference products used for wind validation. After the successful launch, Aeolus winds have been inter-compared with different reference data over many regions. For example, Aeolus winds in the early mission stage were compared with radiosonde observations in different climate zones over the Atlantic Ocean and NWP model equivalents for the Northern Hemisphere, and larger biases were reported for both Ray-clear and Mie-cloudy winds (Baars et al., 2020; Martin et al., 2021). This is associated with the early processing algorithms which have since been developed further to account for such issues. Later, Guo et al. (2021) compared the Aeolus winds with radar wind profiler (RWP) measurements over China, showing that the mean differences are $-0.64 \mathrm{~m} \mathrm{~s}^{-1}$ and $-0.28 \mathrm{~m} \mathrm{~s}^{-1}$ with the standard deviations of $6.82 \mathrm{~m} \mathrm{~s}^{-1}$ and $4.2 \mathrm{~m} \mathrm{~s}^{-1}$ for Rayleigh-clear and

60 Mie-cloudy winds, respectively. Validation was also conducted over the polar regions, and a good agreement with groundbased RWP measurements was obtained in most cases. However, a significant bias of around $7 \mathrm{~m} \mathrm{~s}^{-1}$ during the ascending orbits and a larger random error were found for the Mie channel detection in Antarctica, which is probably due to the sunlight scattering in summer (Belova et al., 2021). More recently, Iwai et al. (2021) validated Aeolus 2B02 and 2B10 wind products by comparing with wind profilers, ground-based coherent Doppler wind lidars, and GPS radiosondes over Japan, and the inter- 
65 comparison with wind profilers and radiosondes showed that the quality of Aeolus winds have been improved in $2 \mathrm{~B} 10$ with both biases and random errors becoming smaller compared with 2B02 product. Although validation and calibration have been carried out over many regions, the data quality of Aeolus measurements across Australia has not been investigated so far.

Moreover, regarding the validation method, most works related to Aeolus are based on inter-comparison analysis. In addition to this, triple collocation analysis is another advantageous method to evaluate space-borne remote sensing products. Unlike inter-comparison that treats a reference dataset free of errors, triple collocation analysis requires three independent measurement systems and assumes that each system contributes to the truth. The outputs are the error standard deviation of each system and calibration relations based on a reference dataset, which can provide valuable information for cost function in data assimilation (Stoffelen, 1998; Vogelzang et al., 2011). Triple collocation analysis has been widely employed to assess

75 the wind measurements from different equipment, including scatterometer, altimeter and radiometer (Caires, 2003; Portabella and Stoffelen, 2009; Ribal and Young, 2020). However, very few studies have evaluated wind products from the space-borne lidar by this method so far.

To complement to earlier validation studies, this research evaluates the Aeolus L2B HLOS wind product over Australia by

80 inter-comparison with ground-based wind profiling radar (WPR) measurements. In addition, a triple collocation analysis for Aeolus HLOS winds is conducted with the help of WPR measurements and NWP model equivalents.

The following sections of this paper proceed as follows: a description of the data and methods used in this study is available in Sect. 2. Key research findings from data analysis are presented in Sect. 3, followed by the discussions in Sect. 4. The final

85 Sect. summarizes the study briefly and draws conclusions.

\section{Data and methods}

\subsection{Aeolus L2B wind product}

To carry out the study, we selected Aeolus Level-2B baseline 11 near real time HLOS winds during the Australian summer from October 2020 to March 2021 for validation because this was the most recent available near real time wind product when

90 conducting this study. The data were obtained from the ESA Aeolus Online Dissemination System (http://aeolusds.eo.esa.int/oads/access/) (ESA, 2021). According to signal-to-noise ratio, Aeolus L2B winds are categorised into four types, which are Rayleigh-clear, Rayleigh-cloudy, Mie-clear and Mie-cloudy winds (de Kloe et al., 2021). The measurements from the Rayleigh channel have better performance in a clear sky (Rayleigh-clear), for which there is little or no contamination from Mie scattering; the wind measurements in the Mie channel need strong backscattering from aerosols, water droplets or ice 95 crystals (Mie-cloudy) (Rennie et al., 2020). In addition, Rayleigh-clear and Mie-cloudy winds are currently the only two types of Aeolus winds that are assimilated into the ECMWF model for operational weather forecast (Rennie et al., 2021). Based on 
these considerations, only Rayleigh-clear and Mie-cloudy winds were extracted for evaluation. The horizontal accumulation along the ground track of each observation is typically $87 \mathrm{~km}$ for Rayleigh winds (which takes 12 seconds) and $15 \mathrm{~km}$ for Mie winds (which takes around 2 seconds), but it may be shorter locally due to the classification in cloudy and clear scenes. Vertically, there are 24 range bins with sizes varying from $250 \mathrm{~m}$ to $2 \mathrm{~km}$. To capture the characteristics of atmospheric circulation over different climate zones, range bin settings vary along the orbit according to geographic location and in time, as requested by special measurement requests and to adapt to seasons and climate zones. Over Australia, there are two different range bin setting regions, i.e., the tropical setting region and the extratropical setting region. The differences in range bin settings are measurement heights and range bin thickness. For tropical setting, the measurements can reach just over $20 \mathrm{~km}$ in height with a range bin size of $750 \mathrm{~m}$ between $12 \mathrm{~km}$ and $15 \mathrm{~km}$ to capture the gravity waves, while the maximum measurement height of the extratropical setting is about $17.5 \mathrm{~km}$ with a higher vertical resolution of $500 \mathrm{~m}$ between $5 \mathrm{~km}$ and $10 \mathrm{~km}$ for jet stream detection (ESA, 2020).

Referring to the existing recommendations for quality control, the HLOS wind speed with a validity flag of 0 and estimated error larger than $8 \mathrm{~m} \mathrm{~s}^{-1}$ for Rayleigh-clear winds and $4 \mathrm{~m} \mathrm{~s}^{-1}$ for Mie-cloudy winds were removed (Rennie and Isaksen, 2020).

\subsection{Wind profiling radar measurements}

Wind profiling radar (WPR) is one of the remote sensing equipment that can measure wind field at three dimensions (Dolman et al., 2018). The Australian WPR network is operated by the Australian Government Bureau of Meteorology, and the data are available at the Centre for Environmental Data Analysis (CEDA) Archive (Met Office, 2008). There are two main types of

115 WRP in the Australian network: Stratospheric Tropospheric Profilers (STP) and Boundary Layer Profilers (BLP) (Dolman et al., 2018). Both are operated at $55 \mathrm{MHz}$. The maximum detection heights of STP are $8 \mathrm{~km}$ for low mode and $20 \mathrm{~km}$ for high mode with a range resolution of $250 \mathrm{~m}$ and $500 \mathrm{~m}$, respectively. For BLP, the maximum detection heights are $7 \mathrm{~km}$ for low mode and $14 \mathrm{~km}$ for high mode with a range resolution of $100 \mathrm{~m}$ and $250 \mathrm{~m}$, respectively. Both types of WPR measurements have been validated and calibrated with radiosonde data, achieving the slope of the least-squares line of best fit close to 1 for both zonal winds and meridional winds and the random difference between WPR and radiosonde data of about $2 \mathrm{~m} \mathrm{~s}^{-1}$ (Dolman et al., 2016). The wind vectors of WPR measurements from the CEDA archive are 30-minute averaged winds.

\subsection{NWP model winds}

In order to carry out the triple collocation analysis, predicted winds were extracted from the Aeolus Auxiliary Meteorological Data (AUX_MET) files. AUX_MET contains forecasted meteorological information at Aeolus observation locations (e.g. temperature and pressure) that is required for processing the L2B product (de Kloe et al., 2021). These meteorological parameters are generated by the fifth generation European Centre for Medium-Range Weather Forecasts (ECMWF) Integrated Forecast System (IFS) model. Predicted winds from the AUX_MET files, rather than model winds from analyses, are selected to avoid dependency between model analysis and observed winds in the validation, i.e., Aeolus winds used for validation have 
not yet been assimilated. In addition, although WPR measurements have been assimilated, the dependency of predicted winds

130 with WPR measurements becomes weaker with forecast time. As a result, these three datasets are assumed independent of each other, which is required for triple collocation analyses. The ECMWF IFS model uses octahedral reduced Gaussian grid $\mathrm{T}_{\mathrm{co}} 1279$ with the grid spacing of about $9 \mathrm{~km}$ at mid-latitudes. Vertically, there are 137 model levels. It is noted that the AUX_MET extracts data from the ECMWF IFS model every 3 seconds along the Aeolus predicted ground track. With moving speed at around $7 \mathrm{~km} \mathrm{~s}^{-1}$ with respect to the surface, each AUX_MET vertical profile is placed at an interval of about $21 \mathrm{~km}$

135 for a given off-nadir prediction (Rennie, 2021). Regarding the data quality, the typical differences between radiosonde and ECMWF winds are 2-3 $\mathrm{m} \mathrm{s}^{-1}$ (Houchi et al., 2010).

\subsection{Collocation criteria}

To carry out error analyses, all data should be collocated both in time and in space. First, the nearest Aeolus L2B wind profiles were extracted based on their distance from WPR sites, which should be less than $75 \mathrm{~km}$ (Zhang et al., 2016), and the vector

140 winds from AUX_MET were extracted from the profiles closest to each Aeolus L2B wind profile. Based on this criterion, there are 6 WPR sites available over Australia, shown in Fig. 1. Over the study period, there should be 5016 Aeolus data samples in total for each detection channel. After quality control based on the criteria in Section 2.1, there are 2171 and 394 data samples remained, accounting for $43.28 \%$ and $7.85 \%$ of the Rayleigh and Mie wind measurements, respectively. The site information and available Aeolus data samples are summarised in Table 1. 


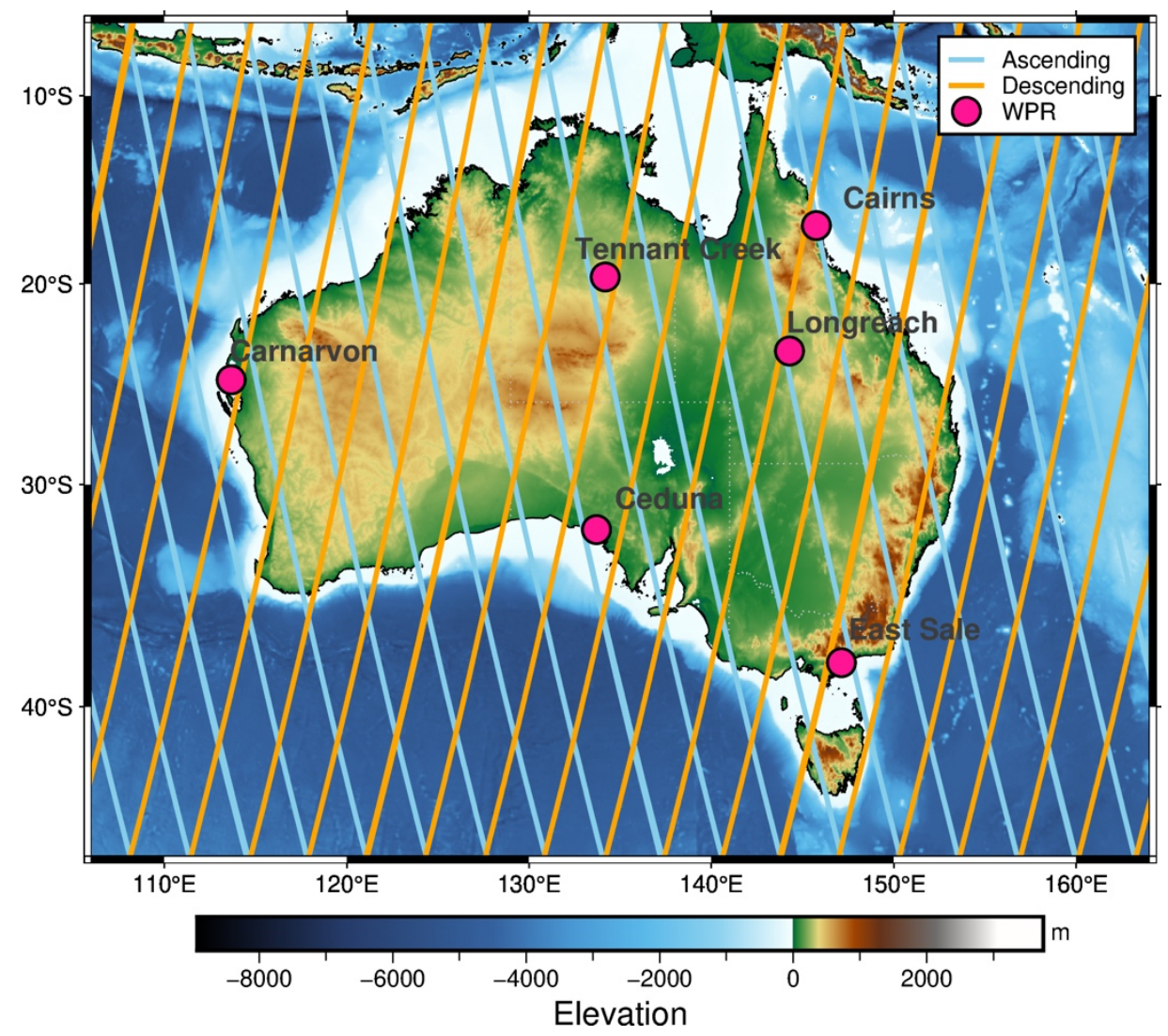

Elevation

Figure 1: Location of wind profiling radars and Aeolus ground tracks over Australia. The pink marks on the map represent the sites of WPR used in this study, and the blue and orange lines indicate the Aeolus ground tracks for ascending and descending orbits, respectively. Shading with different colours represents the earth relief. The elevation data were accessed and the map was created by the authors using PyGMT (Wessel et al., 2019; General Bathymetric Chart of the Oceans (GEBCO) Compilation Group, 2021; Sandwell et al., 2021; Uieda et al., 2021).

Table 1: Information of ground-based WPR sites and Aeolus measurements

\begin{tabular}{|c|c|c|c|c|c|c|c|}
\hline \multirow[b]{2}{*}{$\begin{array}{l}\text { Sites } \\
\text { (Type) }\end{array}$} & \multirow[b]{2}{*}{$\begin{array}{c}\text { Latitude } \\
\quad\left({ }^{\circ}\right)\end{array}$} & \multirow[b]{2}{*}{$\begin{array}{l}\text { Longitude } \\
\quad\left({ }^{\circ}\right)\end{array}$} & \multirow[b]{2}{*}{$\begin{array}{c}\text { Elevation } \\
\text { (m) }\end{array}$} & \multicolumn{2}{|c|}{ Aeolus Ascending } & \multicolumn{2}{|c|}{ Aeolus Descending } \\
\hline & & & & $\begin{array}{c}\text { Overpass } \\
\text { time (UTC) }\end{array}$ & $\begin{array}{c}\text { Available samples } \\
\text { (Rayleigh/Mie) }\end{array}$ & $\begin{array}{c}\text { Overpass } \\
\text { time (UTC) }\end{array}$ & $\begin{array}{c}\text { Available samples } \\
\text { (Rayleigh/Mie) }\end{array}$ \\
\hline $\begin{array}{c}\text { Longreach } \\
\text { (STP) }\end{array}$ & -23.44 & 144.28 & 192 & $\begin{array}{c}\text { 08:41 } \\
\text { Thursday }\end{array}$ & $301 / 57$ & $\begin{array}{c}\text { 20:01 } \\
\text { Wednesday }\end{array}$ & $320 / 15$ \\
\hline $\begin{array}{c}\text { Carnarvon } \\
\text { (STP) }\end{array}$ & -24.89 & 113.67 & 4 & - & - & $\begin{array}{l}22: 00 \\
\text { Friday }\end{array}$ & $368 / 13$ \\
\hline $\begin{array}{c}\text { Tennant } \\
\text { Creek } \\
\text { (STP) }\end{array}$ & -19.64 & 134.18 & 376 & - & - & $\begin{array}{c}\text { 20:40 } \\
\text { Saturday }\end{array}$ & $151 / 35$ \\
\hline
\end{tabular}


https://doi.org/10.5194/amt-2022-63

Preprint. Discussion started: 25 February 2022

(c) Author(s) 2022. CC BY 4.0 License.

(c) (i)

\section{Atmospheric Measurement Techniques \\ Discussions}

\begin{tabular}{|c|c|c|c|c|c|c|c|}
\hline $\begin{array}{l}\text { Cairns } \\
\text { (BLP) }\end{array}$ & -16.95 & 145.75 & 4 & $\begin{array}{c}08: 31 \\
\text { Wednesday }\end{array}$ & $198 / 94$ & $\begin{array}{c}\text { 20:00 } \\
\text { Wednesday }\end{array}$ & $173 / 49$ \\
\hline $\begin{array}{c}\text { East Sale } \\
\text { (BLP) }\end{array}$ & -38.12 & 147.13 & 5 & $\begin{array}{c}\text { 08:37 } \\
\text { Thursday }\end{array}$ & $245 / 56$ & $\begin{array}{c}\text { 19:40 } \\
\text { Monday }\end{array}$ & $321 / 49$ \\
\hline $\begin{array}{l}\text { Ceduna } \\
\text { (BLP) }\end{array}$ & -32.13 & 133.70 & 15 & $\begin{array}{c}\text { 09:32 } \\
\text { Monday }\end{array}$ & $94 / 26$ & - & - \\
\hline
\end{tabular}

Then, wind vectors from WPR and AUX_MET were converted to HLOS winds by using the following Eq. (1):

$$
\text { HLOS }=-u_{\text {Ref }} \sin A-v_{\text {Ref }} \cos A
$$

155 where A is the azimuth angle of the Aeolus satellite, Ref represents either to WPR or AUX_MET. The geometry of Aeolus wind measurements is shown in Fig. 2.
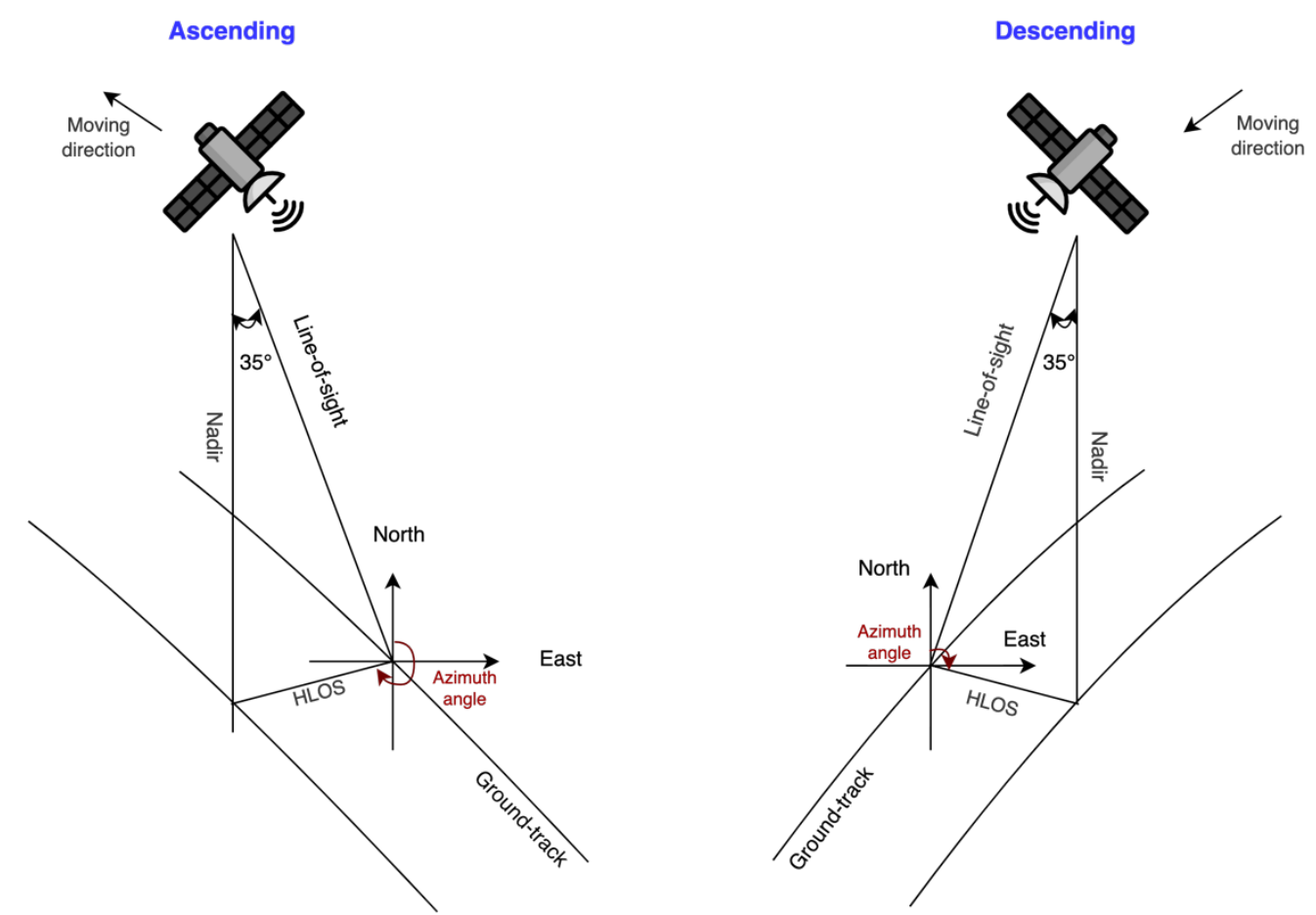

Figure 2: Geometry of Aeolus wind measurements.

Vertically, the HLOS winds from WPR and AUX_MET were converted to winds corresponding to Aeolus range bins by averaging the winds between the top and bottom heights of each vertical bin, shown in Fig. 3. 


\section{$2125 \mathrm{~m}$}

Bin 22

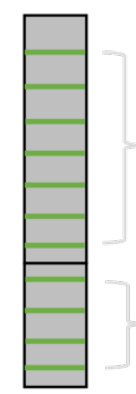

\section{Average}

\section{$1118 \mathrm{~m}$}

Bin 23

\section{Average}

\section{$614 \mathrm{~m}$}

Figure 3: Sketch map of WPR and AUX_MET wind conversion to Aeolus range bins, where green bars represent the heights of WPR or AUX_MET winds.

\subsection{Inter-comparison analysis}

165 For inter-comparison analysis, we assumed that WPR is the ground truth. After data filtering and collocation, we quantified the mean bias (BIAS), standard deviation of wind difference (SD), scaled median absolute deviation (scaled-MAD) and correlation coefficient (R) of both Rayleigh-clear winds and Mie-cloudy winds based on Eq. (2), Eq. (3), Eq. (4) and Eq. (5). In this study, we use scaled-MAD to represent random error because it is a robust statistic to measure data variability. When random errors are purely Gaussian distributed, scaled-MAD is identical to SD; while in case the distribution is not purely Gaussian, scaled-MAD is less sensitive to outliers (Ruppert, 2011).

$$
\begin{aligned}
& \text { BIAS }=\frac{1}{\mathrm{~N}} \sum_{\mathrm{i}=1}^{\mathrm{N}}\left(\operatorname{HLOS}_{\text {Aeolus }, \mathrm{i}}-\operatorname{HLOS}_{\text {Ref }, \mathrm{i}}\right) \\
& \mathrm{SD}=\sqrt{\frac{1}{\mathrm{~N}-1} \sum_{\mathrm{i}=1}^{\mathrm{N}}\left(\left(\operatorname{HLOS}_{\text {Aeolus }, \mathrm{i}}-\operatorname{HLOS}_{\text {Ref }, \mathrm{i}}\right)-\mathrm{BIAS}\right)^{2}} \\
& \text { scaled_MAD }=1.4826 \times \operatorname{median}\left(\left|\left(\operatorname{HLOS}_{\text {Aeolus }, \mathrm{i}}-\operatorname{HLOS}_{\text {Ref,i }}\right)-\operatorname{median}\left(\operatorname{HLOS}_{\text {Aeolus }, \mathrm{i}}-\operatorname{HLOS}_{\text {Ref,i }}\right)\right|\right) \\
& \mathrm{R}=\frac{\sum_{\mathrm{i}=1}^{\mathrm{N}}\left(\mathrm{HLOS}_{\text {Aeolus }, \mathrm{i}}-\overline{\mathrm{HLOS}_{\text {Aeolus }}}\right)\left(\mathrm{HLOS}_{\text {Ref }, \mathrm{i}}-\overline{\mathrm{HLOS}_{\text {Ref }}}\right)}{\sqrt{\sum_{\mathrm{i}=1}^{\mathrm{N}}\left(\mathrm{HLOS}_{\text {Aeolus }, \mathrm{i}}-\overline{\mathrm{HLOS}_{\text {Aeolus }}}\right)^{2}} \sqrt{\sum_{\mathrm{i}=1}^{\mathrm{N}}\left(\mathrm{HLOS}_{\text {Ref }, \mathrm{i}}-\overline{\mathrm{HLOS}_{\text {Ref }}}\right)^{2}}}
\end{aligned}
$$

where subscript Ref represents WPR; $\mathrm{N}$ is the total number of data points; $i$ is from 1,2,3.., N.

The analysis is for all data, but also separated in ascending and descending orbits. In addition, errors as a function of height were also investigated. Since Aeolus observations over Australia have different vertical range bins settings for tropical and extratropical regions, we defined 12 new range bins and grouped HLOS winds from their original range bins to defined range bins based on their centre of gravity (COG) heights. The uncertainty of bias for each range bin is calculated by Eq. (6). 


$$
\text { Uncertainty }=\frac{S D}{\sqrt{N}}
$$

\subsection{Triple collocation analysis}

185 To carry out triple collocation analysis, two other measurement systems are required besides Aeolus. In this study, they are WPR measurements and ECMWF IFS model equivalents. The temporal and spatial resolutions of these three systems are summarised in Table 2. We choose WPR measurement as the reference, which is the system 1. Aeolus L2B winds and NWP winds are system 2 and system 3, respectively. All three systems are linearly correlated with the true HLOS winds, which can be described by Eq. (7), Eq. (8) and Eq. (9).

$$
\begin{gathered}
\operatorname{HLOS}_{1}=T+e_{1} \\
\mathrm{HLOS}_{2}=a_{2}+b_{2} T+e_{2} \\
\mathrm{HLOS}_{3}=a_{3}+b_{3} T+e_{3}
\end{gathered}
$$

where $T$ is the true value of HLOS winds; $a_{i}$ and $b_{i}$ are the intercept and the slope of the calibration for each system; $e_{i}$ is the random error of each system.

Table 2: Spatial and temporal resolution of the three datasets

\begin{tabular}{cccc}
\hline & 1: WPR & 2: Aeolus L2B & 3: AUX_MET \\
\hline Horizontal & Point-based & $87 \mathrm{~km}$ (Rayleigh) $/ 10-15 \mathrm{~km}(\mathrm{Mie})$ & $\sim 90 \mathrm{~km}$ \\
Vertical & $100 / 250 / 500 \mathrm{~m}$ & From $250 \mathrm{~m}$ to $2 \mathrm{~km}$ & 137 model levels \\
Temporal & 30 minutes & $\sim 10$ seconds $/ \sim 1-2$ seconds & Instantaneous \\
\hline
\end{tabular}

The method and equation derivation of triple collocation analysis are formulated in Vogelzang and Stoffelen (2012). To simplify the study, we assume the true measurement errors of each system are independent. Hence, no representation error contributes to the error covariances. Thus, the equations to calculate the error standard deviation of each system can be simplified to Eq. (10), Eq. (11) and Eq. (12).

$$
\begin{aligned}
& \sigma_{1}=\sqrt{\left\langle e_{1}^{2}\right\rangle}=\sqrt{C_{11}-\frac{C_{12} C_{13}}{C_{23}}} \\
& \sigma_{2}=\sqrt{\left\langle e_{2}^{2}\right\rangle}=\sqrt{C_{22}-\frac{C_{12} C_{23}}{C_{13}}} \\
& \sigma_{3}=\sqrt{\left\langle e_{3}^{2}\right\rangle}=\sqrt{C_{33}-\frac{C_{23} C_{13}}{C_{12}}}
\end{aligned}
$$


205 where $C_{i i}$ is the variance of each system, and $C_{i j}$ is the covariance between the system i and $\mathrm{j}$; and $\langle>$ represents the statistical averaging.

The calibration coefficients can be described by Eq.(13), Eq.(14), Eq.(15) and Eq.(16), and the calibration relations are shown in Eq.(17) and Eq.(18).

$$
\begin{gathered}
b_{2}=\frac{C_{23}}{C_{13}} \\
b_{3}=\frac{C_{23}}{C_{12}} \\
a_{2}=\left\langle H L O S_{2}\right\rangle-b_{2}\left\langle H L O S_{1}\right\rangle \\
a_{3}=\left\langle\operatorname{LOS}_{3}\right\rangle-b_{3}\left\langle\operatorname{HLS}_{1}\right\rangle
\end{gathered}
$$

$$
\begin{aligned}
& \operatorname{HLOS}_{2}^{*}=\frac{H L O S_{2}}{b_{2}}-\frac{a_{2}}{b_{2}} \\
& \operatorname{HLOS}_{3}^{*}=\frac{H L O S_{3}}{b_{3}}-\frac{a_{3}}{b_{3}}
\end{aligned}
$$

where $\operatorname{HLOS}_{2}^{*}$ and $\mathrm{HLOS}_{3}^{*}$ are the calibrated wind speed of system 2 and system 3.

\subsection{Wind variability analysis}

220 Wind observations are closely connected to the local atmospheric conditions. To investigate the influence of convection on Aeolus wind measurements, for every Mie or Rayleigh spatial sample, we employed the wind vectors from WPR measurements \pm 2 hours around the collocation points to quantify wind variability in each component and the turbulence kinetic energy (TKE), see Eq. (19), Eq. (20), Eq. (21) and Eq. (22). The results were averaged for Mie and Rayleigh channels, and the student t-test was performed.

$$
\begin{gathered}
\operatorname{Var}(u)=\frac{\sum_{i=1}^{n}\left(u_{i}-\bar{u}\right)^{2}}{n} \\
\operatorname{Var}(v)=\frac{\sum_{i=1}^{n}\left(v_{i}-\bar{v}\right)^{2}}{n} \\
\operatorname{Var}(w)=\frac{\sum_{i=1}^{n}\left(w_{i}-\bar{w}\right)^{2}}{n} \\
T K E=\frac{\operatorname{Var}(u)+\operatorname{Var}(v)+\operatorname{Var}(w)}{2}
\end{gathered}
$$

where $u_{i}, v_{i}$ and $w_{i}$ are WPR east-west, north-south and vertical winds at each time step (30 minutes) of \pm 2 hours ( $\left.\mathrm{n}=9\right)$ around the collocation points, and $\bar{u}, \bar{v}$ and $\bar{w}$ are the corresponding mean winds, respectively. 


\section{Results}

After filtering out the invalid data and collocating all HLOS winds from three data sets, the results are based on 1011 matchup samples of Rayleigh-clear winds and 224 match-up samples of Mie-cloudy winds.

\subsection{Inter-comparison}

235 The results of the inter-comparison analysis with WPR being the ground truth are summarised in Table 3 and presented in Fig. 4. From the scatter plots, it can be seen that the winds detected by the Rayleigh channel range from $-40 \mathrm{~m} \mathrm{~s}^{-1}$ to $60 \mathrm{~m} \mathrm{~s}^{-1}$, while the wind speed from the Mie channel are lower, mainly ranging between $-20 \mathrm{~m} \mathrm{~s}^{-1}$ and $30 \mathrm{~m} \mathrm{~s}^{-1}$. Overall, both Rayleigh-clear winds and Mie-cloudy winds are in good agreement with WRP measurements with R larger than 0.9 for all data. For Rayleighclear winds, the overall bias is $-0.48 \mathrm{~m} \mathrm{~s}^{-1}$ with a SD of $6.22 \mathrm{~m} \mathrm{~s}^{-1}$ and a scaled MAD of $5.81 \mathrm{~m} \mathrm{~s}^{-1}$. A large bias $\left(-0.71 \mathrm{~m} \mathrm{~s}^{-1}\right)$

240 was found during descending orbit, but no significant difference in random errors was detected during ascending and descending orbits. For Mie-cloudy winds, the bias for all data is $0.70 \mathrm{~m} \mathrm{~s}^{-1}$, and the SD and the scaled MAD are $4.77 \mathrm{~m} \mathrm{~s}^{-1}$ and $4.14 \mathrm{~m} \mathrm{~s}^{-1}$, respectively. Moreover, the Mie channel has better performance on descending orbits (Bias: $-0.25 \mathrm{~m} \mathrm{~s}^{-1}$; scaled MAD: $3.63 \mathrm{~m} \mathrm{~s}^{-1}$ ) than ascending orbits (Bias: $1.35 \mathrm{~m} \mathrm{~s}^{-1}$; scaled MAD: $4.11 \mathrm{~m} \mathrm{~s}^{-1}$ ).

Table 3: Results of intercomparison with ground-based WPR measurements.

\begin{tabular}{llccccc}
\hline & Orbit & Bias $\left[\mathbf{m ~ s}^{-1}\right]$ & SD $\left[\mathbf{m ~ s}^{-1}\right]$ & Scaled MAD & R & N \\
\hline Rayleigh & All & -0.48 & 6.22 & 5.81 & 0.92 & 1011 \\
& Ascending & -0.06 & 6.59 & 5.76 & 0.89 & 368 \\
& Descending & -0.71 & 5.99 & 5.73 & 0.88 & 643 \\
\hline Mie & All & 0.70 & 4.77 & 4.14 & 0.90 & 224 \\
& Ascending & 1.35 & 4.77 & 4.11 & 0.86 & 132 \\
& Descending & -0.25 & 4.64 & 3.63 & 0.90 & 92 \\
\hline
\end{tabular}


https://doi.org/10.5194/amt-2022-63

Preprint. Discussion started: 25 February 2022

(c) Author(s) 2022. CC BY 4.0 License.
Atmospheric

Measurement

Techniques

Discussions (a) Rayleigh, All data

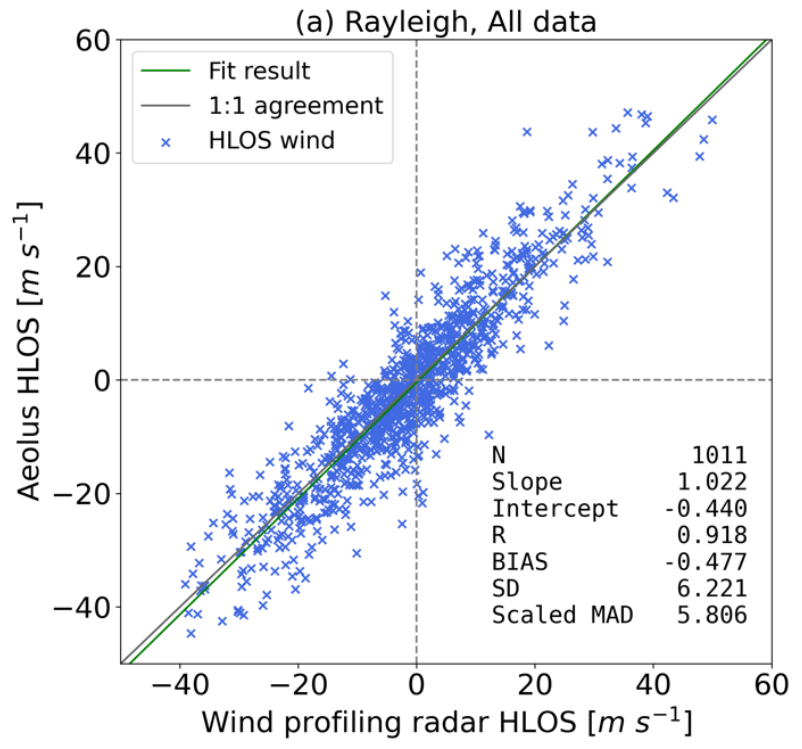

(c) Rayleigh, ascending

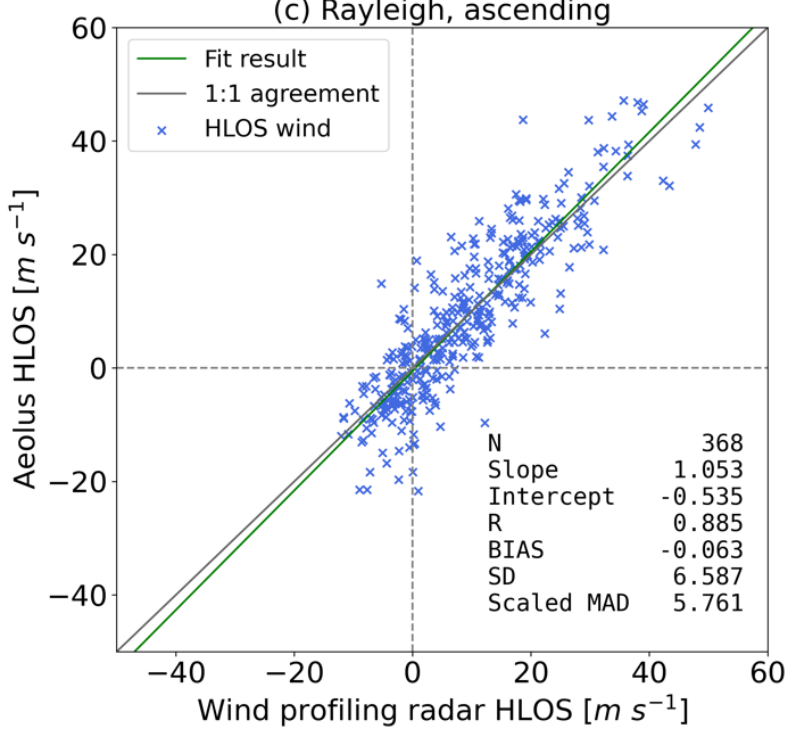

(b) Mie, All data

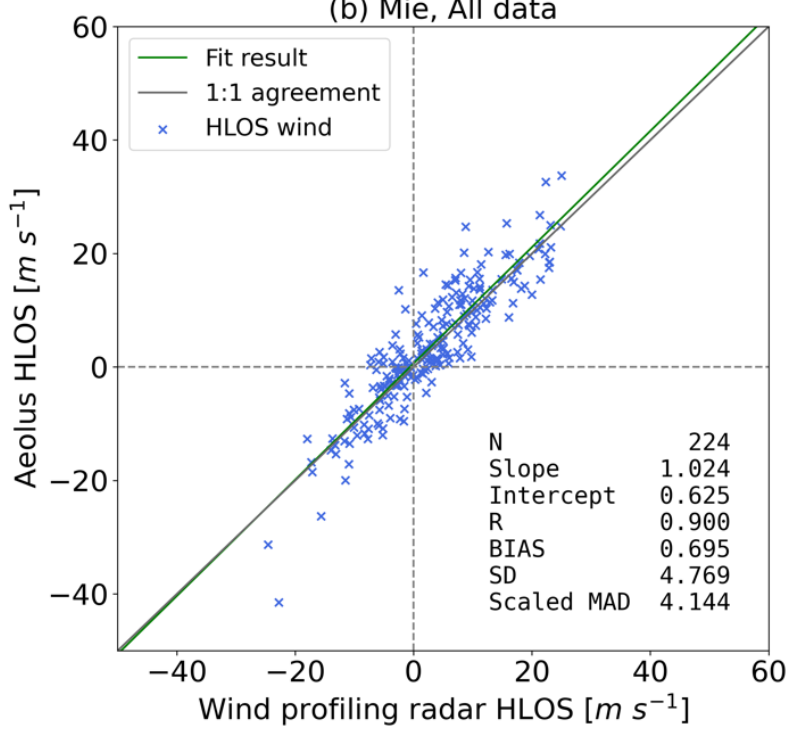

(d) Mie, ascending

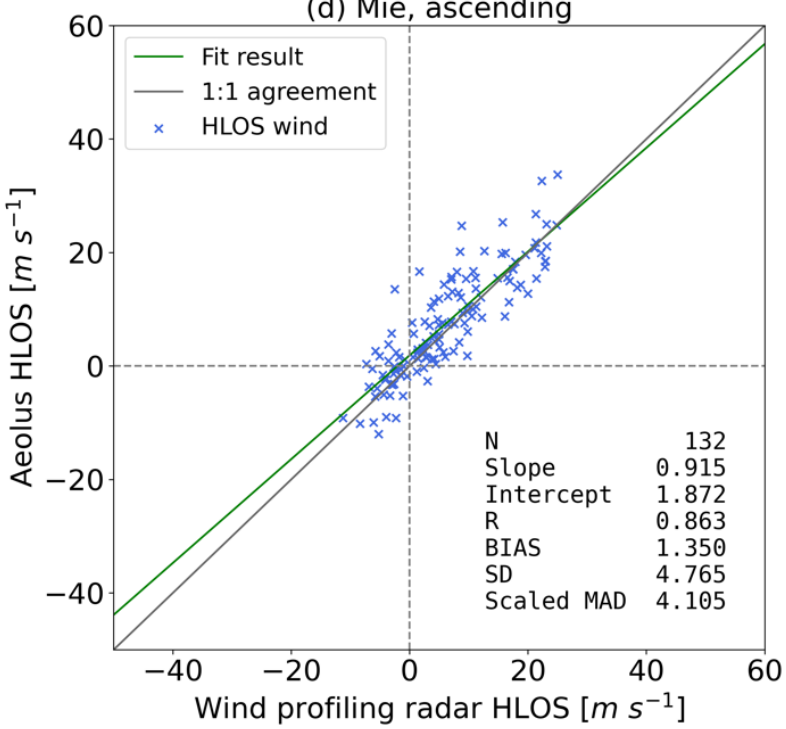



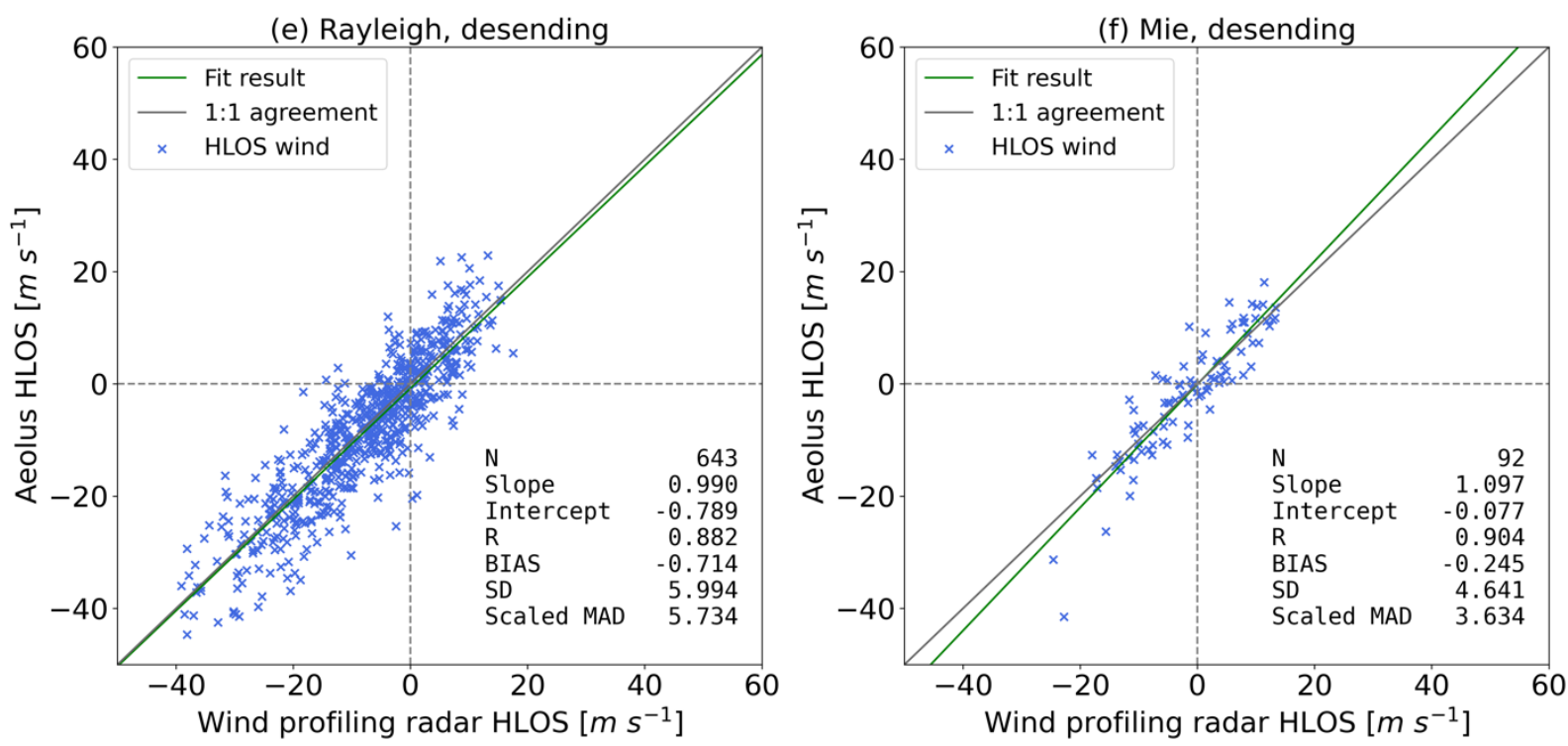

Figure 4: Scatter plots of Aeolus HLOS winds against WPR HLOS winds for all data, ascending orbits and descending orbits. Plot (a), (c) and (e) are for the Rayleigh-clear winds, and (b), (d) and (f) are for the Mie-cloudy winds. Green and grey lines indicate the fitted regression result and 1:1 agreement, respectively.

Figure 5 gives information about wind difference as a function of height for all data, ascending and descending orbits. Overall, there are more valid paired samples from the Rayleigh channel, except for the height below $750 \mathrm{~m}$. Most of the Rayleigh-WPR samples distribute between 1,500 $\mathrm{m}$ and 20,000 m, while Mie-WPR samples mainly distribute below 10,000 m.

Regarding the bias at each height, the Aeolus Rayleigh channel tends to underestimate the wind speed by $\sim 1.7 \mathrm{~m} \mathrm{~s}^{-1}$ between $750 \mathrm{~m}$ and 7,500 $\mathrm{m}$ for ascending orbits and by $\sim 0.8 \mathrm{~m} \mathrm{~s}^{-1}$ between $1,500 \mathrm{~m}$ and $10,000 \mathrm{~m}$ for descending orbits, with the scaled MAD fluctuating at around $5 \mathrm{~m} \mathrm{~s}^{-1}$. Above 10,000 m, for most heights, biases and scaled MADs become larger and/or more variable for Rayleigh wind match-ups. For the Mie channel, winds tend to be overestimated by Aeolus between $750 \mathrm{~m}$ and 10,000 m with biases of $\sim 1.8 \mathrm{~m} \mathrm{~s}^{-1}$ for ascending orbits and $\sim 0.6 \mathrm{~m} \mathrm{~s}^{-1}$ for descending orbits except for the heights 6,000 $\mathrm{m}-7,500 \mathrm{~m}$, and the scaled MADs are almost within $5 \mathrm{~m} \mathrm{~s}^{-1}$. Wind underestimation and smaller scaled MADs were found below $750 \mathrm{~m}$ and above $10,000 \mathrm{~m}$ for both orbits for the Mie channel. 
https://doi.org/10.5194/amt-2022-63

Preprint. Discussion started: 25 February 2022

(C) Author(s) 2022. CC BY 4.0 License.

(c) (1)
Atmospheric Measurement Techniques Discussions (a) All data

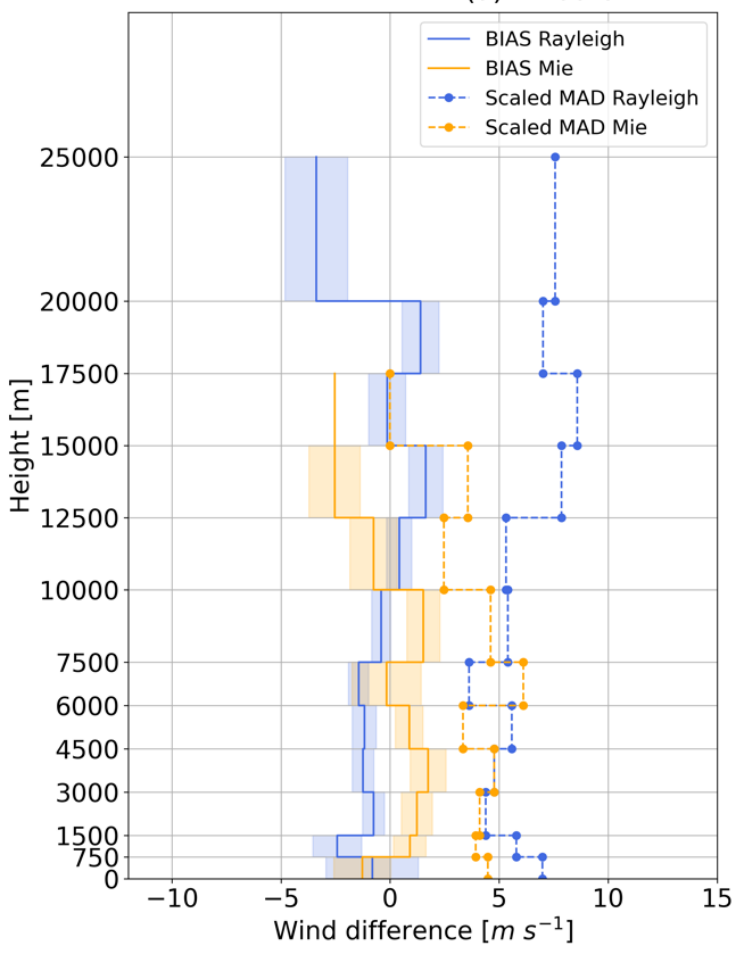

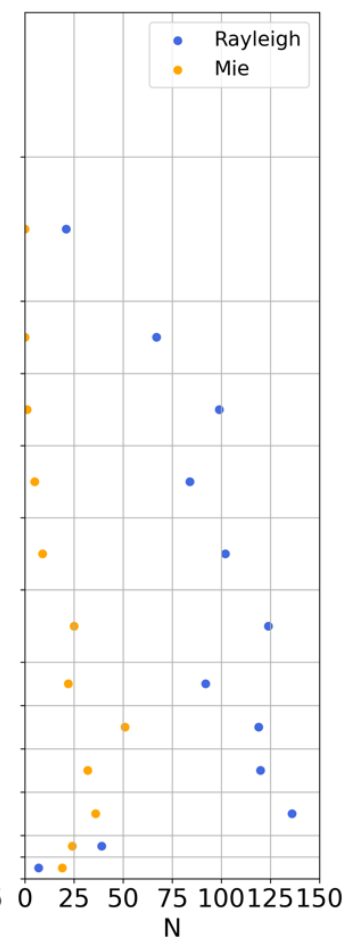


https://doi.org/10.5194/amt-2022-63

Preprint. Discussion started: 25 February 2022

(C) Author(s) 2022. CC BY 4.0 License.

(c) (1)
Atmospheric Measurement Techniques Discussions

265

(b) Ascending
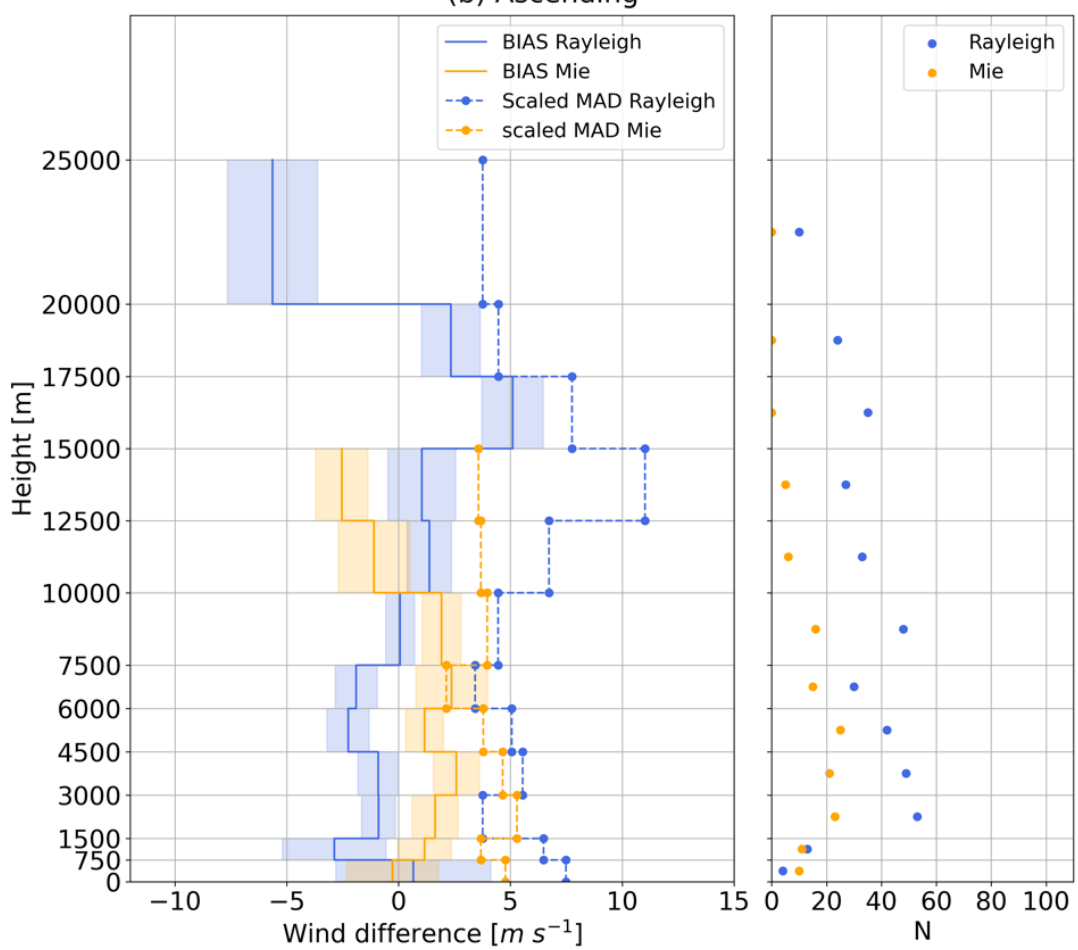
(c) Descending

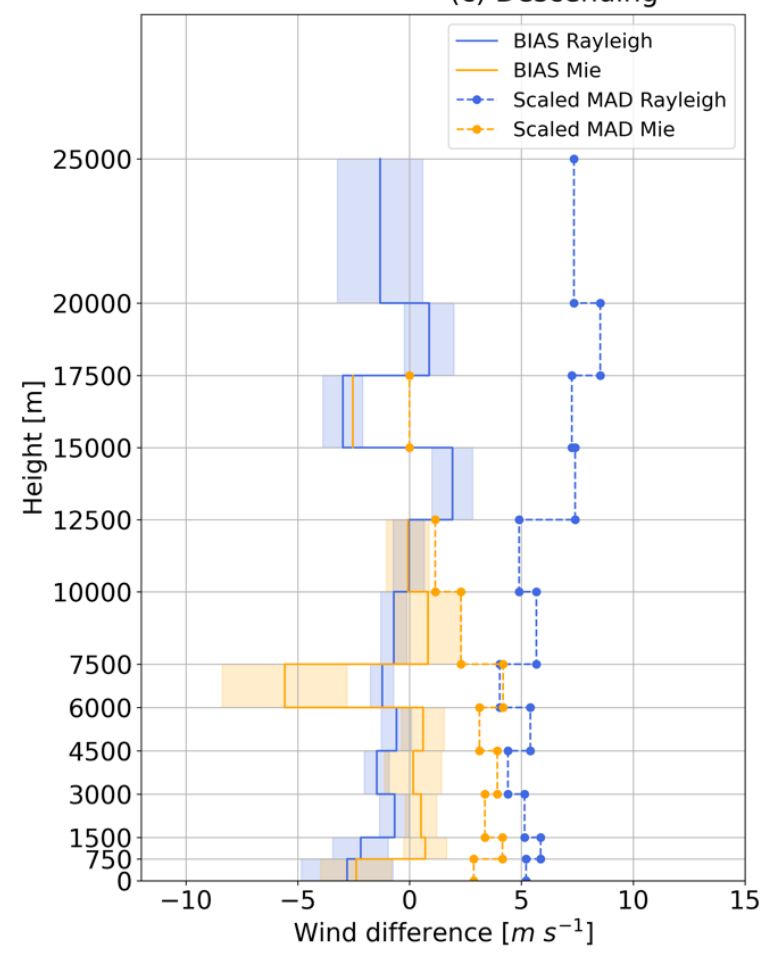

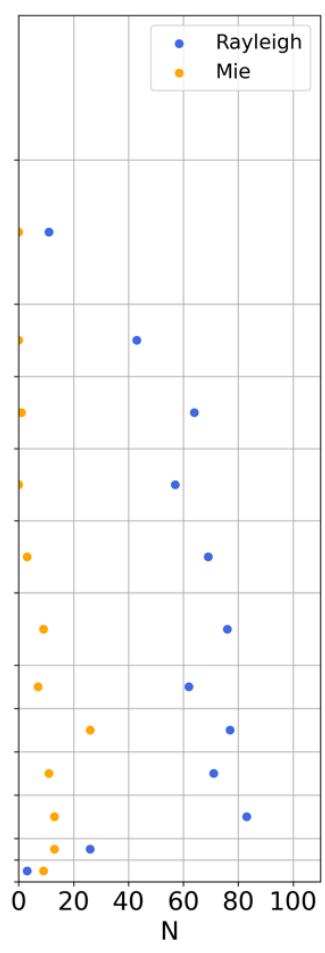

Figure 5: Wind differences (Aeolus-WPR) with height for (a) all data, (b) ascending orbits and (c) descending orbits. Left:

Mean bias and scaled MAD of wind difference as a function of height with shading area representing the uncertainty. Right: the number of available match-ups at each height. Blue and orange colours indicate the data for the Rayleigh and Mie channels, respectively.

\subsection{Triple collocation}

The result of the triple collocation analysis is shown in Table 4. For the combination of Rayleigh-clear winds, WPR and NWP model equivalents, the Aeolus measurements have the largest error standard deviation of $5.61 \mathrm{~m} \mathrm{~s}^{-1}$ followed by WPR observations of $2.01 \mathrm{~m} \mathrm{~s}^{-1}$. NWP model equivalent is most accurate with an error standard deviation of $1.17 \mathrm{~m} \mathrm{~s}^{-1}$. Similar results were also obtained from the combination with Mie-cloudy winds, and the error standard deviations are $3.50 \mathrm{~m} \mathrm{~s}^{-1}, 2.60$ $\mathrm{m} \mathrm{s}^{-1}$ and $1.70 \mathrm{~m} \mathrm{~s}^{-1}$ for Aeolus measurements, WPR observations and NWP model equivalents, respectively.

Table 4: Error standard deviation of three different systems $\left(\mathrm{m} \mathrm{s}^{-1}\right)$

\begin{tabular}{ccccc}
\hline & 1: WPR & 2: Aeolus L2B & 3: AUX_MET & N \\
\hline Rayleigh-clear & 2.01 & 5.61 & 1.17 & 1011 \\
Mie-cloudy & 2.60 & 3.50 & 1.70 & 224 \\
\hline
\end{tabular}

280 The calibration coefficients and relations for Aeolus L2B and NWP winds are shown in Table 5. For Rayleigh wind comparison, the Aeolus and the NWP model have similar patterns in wind estimation with intercepts of $-0.404 \mathrm{~m} \mathrm{~s}^{-1}$ and - 
$0.236 \mathrm{~m} \mathrm{~s}^{-1}$ and slopes of 1.044 and 1.033, respectively. Regarding the Mie wind comparison, the intercepts are $0.388 \mathrm{~m} \mathrm{~s}^{-1}$ and $0.064 \mathrm{~m} \mathrm{~s}^{-1}$ with the slopes of 1.106 and 1.075 for the Aeolus and the NWP model winds, respectively.

Table 5: Calibration coefficients of Aeolus L2B and NWP winds

\begin{tabular}{ccccccc}
\hline & \multicolumn{4}{c}{ 2: Aeolus L2B } & \multicolumn{3}{c}{ 3: NWP } \\
\cline { 2 - 7 } & $\mathbf{a 2}$ & $\mathbf{b 2}$ & $\boldsymbol{H L O S}_{\mathbf{2}}^{*}$ & $\mathbf{a 3}$ & $\mathbf{b 3}$ & HLOS $_{\mathbf{3}}^{*}$ \\
\hline Rayleigh-clear & -0.404 & 1.044 & $0.958 \mathrm{HLOS} 2+0.387$ & -0.236 & 1.033 & $0.968 \mathrm{HLOS3}+0.228$ \\
Mie-cloudy & 0.388 & 1.106 & $0.904 \mathrm{HLOS} 2-0.351$ & 0.064 & 1.075 & $0.930 \mathrm{HLOS} 3-0.060$ \\
\hline
\end{tabular}

\subsection{Wind variability}

According to Table 6, all statistics of WPR wind variability for Mie-cloudy winds are higher than that of Rayleigh-clear winds, but only the difference in $\mathrm{w}$ wind component is statistically significant (p-value $<0.001$ ). Overall, it suggests that the atmosphere may have larger variability during Mie-cloudy wind sampling.

Table 6: Results of wind variability based on WPR measurements $\left(\mathrm{m}^{2} \mathrm{~s}^{-2}\right)$

\begin{tabular}{ccccc}
\hline & Var $(\mathbf{u})$ & Var $(\mathbf{u})$ & Var $(\mathbf{w})$ & TKE \\
\hline Rayleigh-clear & 2.24 & 2.09 & 0.01 & 2.15 \\
Mie-cloudy & 2.48 & 2.45 & 0.03 & 2.48 \\
p-value & 0.358 & 0.181 & $<0.001$ & 0.110 \\
\hline
\end{tabular}

\section{Discussion}

The findings from the inter-comparison analysis indicate that both Rayleigh-clear and Mie-cloudy winds are in good agreement with the ground-based radar measurements with the biases for all data meeting the mission requirement of $0.7 \mathrm{~m} \mathrm{~s}^{-1}$ (Ingmann and Straume, 2016). However, the random errors represented by scaled MADs from both channels are larger than the specified random error of $<3 \mathrm{~m} \mathrm{~s}^{-1}$ below $20 \mathrm{~km}$ (Ingmann and Straume, 2016), especially from the Rayleigh detection channel. These results are in line with many existing studies over different regions (Baars et al., 2020; Guo et al., 2021; Iwai et al., 2021; Chen et al., 2021). The large random errors are mainly because of unwanted signal losses in the instrument transmission and detection chain since the Aeolus launch (Krisch and Aeolus DISC, 2020), which impact the wind quality, especially for the Rayleigh channel. Regarding the performance during different orbit phases, a larger absolute mean bias was found during descending orbits, which is consistent with the results for the Northern Hemisphere (Martin et al., 2021), but the magnitudes of the biases $\left(<1 \mathrm{~m} \mathrm{~s}^{-1}\right)$ are smaller in this study. No significant difference in random errors was found from Rayleigh-clear winds. For Miecloudy winds, a large mean bias $\left(1.35 \mathrm{~m} \mathrm{~s}^{-1}\right)$ and random error $\left(4.11 \mathrm{~m} \mathrm{~s}^{-1}\right)$ were identified during ascending orbits. One possible reason would be different representativeness conditions in the morning (descending) and afternoon (ascending). Figure 4 (d) 
and (f) show different wind distributions during ascending and descending orbits, hence suggesting a different circulation in the morning (descending) and afternoon (ascending). Moreover, Fig. 5 shows clouds peak at about $5 \mathrm{~km}$ height during descending orbits (at about 6:00 LT), while during ascending orbits, there are more uniform clouds from $2 \mathrm{~km}$ to $8 \mathrm{~km}$ height at the end of the day (at 18:00 LT). So, the meteorological conditions during Mie wind measurements for the ascending and descending orbit phases appear quite different, which may imply different representativeness conditions and hence different random errors.

For vertical distributions of wind difference, Mie-cloudy winds are more precise compared with Rayleigh-clear winds below 1,500 $\mathrm{m}$ for all data, which is consistent with the studies for China and Japan (Iwai et al., 2021; Wu et al., 2022). Below 750 $\mathrm{m}$, large biases both for Rayleigh-clear and Mie-cloudy winds were found during descending orbits. This low accuracy may be related to the inhomogeneous topography at Cairns and at East Sale, which may have a larger impact on descending wind measurements, shown in Fig. 1. Moreover, the higher accuracy of Mie-cloudy winds during both ascending and descending orbits suggest that the Mie channel is more capable of capturing winds within the planetary boundary layer (PBL). This may also suggest the potential large impact of Mie-cloudy winds on data assimilation at these heights. In addition, during the descending orbit phase, for the Mie channel, the biases between $750 \mathrm{~m}$ and 6,000 m are smaller than $0.7 \mathrm{~m} \mathrm{~s}^{-1}$, achieving the mission requirement.

Regarding the vertical distributions of available match-ups, most Rayleigh-WPR match-ups are distributed between 1,500 $\mathrm{m}$ and 20,000 m, since below 1,500 m less Rayleigh-clear winds are available due to the attenuation of the molecular signal because of Mie scattering within the PBL. Above 1,500 m, the number of available match-ups decreases with height. This is because the maximum measurement height of BLP is $7 \mathrm{~km}(10 \mathrm{~km})$ and of STP is $8 \mathrm{~km}(20 \mathrm{~km})$ for the low mode (high mode), so fewer data samples are available at higher heights. For match-ups associated with Mie-cloudy winds, the majority of data pairs distributes below $10,000 \mathrm{~m}$, which is consistent with where Mie-scattering is expected to take place.

The error standard deviations or random errors estimated by the triple collocation analysis for Rayleigh-clear winds $\left(5.61 \mathrm{~m} \mathrm{~s}^{-}\right.$ $\left.{ }^{1}\right)$ and Mie-cloudy winds $\left(3.50 \mathrm{~m} \mathrm{~s}^{-1}\right)$ are roughly comparable with the results from intercomparison analysis $\left(5.81 \mathrm{~m} \mathrm{~s}^{-1}\right.$ for 330 Rayleigh-clear winds and $4.14 \mathrm{~m} \mathrm{~s}^{-1}$ for Mie-cloudy winds), indicating the Mie-cloudy winds are more precise than Rayleighclear winds. For the WPR, the temporal and spatial representation errors associated with the collocation criteria and the aggregated Aeolus observations are the main contribution to the random errors. The NWP random errors obtained are in line with expectations. If we take spatial representation error into account, Skamarock (2004) argues that the effective spatial resolution of a model is 7-10 times the grid distance, thus the horizontal resolution of Aeolus measurements for Rayleigh-clear 335 winds and NWP model equivalents are almost alike, with the WPR resolving small-scale variance not detected by the Aeolus nor the NWP model. Given the coarse NWP resolution, the common variance of the coarse Rayleigh-clear winds and WPR will be small, and hence the impact of representativeness error on the Rayleigh comparison is limited. For the Mie comparison, 
the remaining common variance between the moderate-resolution Mie-cloudy winds and WPR is not resolved by the NWP model, which is coarsest, leading to the higher error standard deviation of NWP. If we assume a spatial representativeness $2.79 \mathrm{~m} \mathrm{~s}^{-1}$ and $3.64 \mathrm{~m} \mathrm{~s}^{-1}$ for NWP, WPR and Mie-cloudy winds, respectively. Compared with the results of triple collocation for Rayleigh winds, the random errors for NWP and WPR are higher. The study from Lin et al. (2016) explicitly showed that model wind accuracy near the ocean surface over convective areas is 4 times larger than that of clear areas. Moreover, based on the wind variability results in section 3.3, these higher values may be related to the vertical wind shear and convective conditions during Mie wind sampling. Additionally, the number of collocated samples for Mie comparison is just 224, which is much lower than the optimal amount (at least 1,000 samples) for triple collocation analysis, thus the results contain some uncertainty.

This study is based on the Aeolus near real time 2B11 data. It is known that Mie-cloudy winds show systematic biases, for which a solution is in place for operational processing since July 2021 (Marseille et al., 2022), which is outside the study period. In order to evaluate whether these systematic errors impact the current validation results, we applied the correction method to the near real time 2B11 data to yield corrected Mie winds. The method of correction and validation results are shown in Appendix A. These results do not affect above discussion.

\section{Conclusions}

With the successful launch and operation of the Aeolus satellite, this study was undertaken to evaluate the Level-2B baseline 11 HLOS wind product during the Australian summer from October 2020 to March 2021. To achieve this, the Aeolus Rayleighclear and Mie-cloudy winds were inter-compared with ground-based WPR measurements. In addition, triple collocation analysis was attempted for the combination of Aeolus winds (Rayleigh-clear and Mie-cloudy), WPR measurements and NWP model equivalents.

When comparing with the ground-based radar measurements, no significant biases (absolute mean bias $<0.7 \mathrm{~m} \mathrm{~s}^{-1}$ ) and good agreements $(\mathrm{R}>0.9)$ were found for both Rayleigh-clear and Mie-cloudy winds. For the Rayleigh channel, the wind detection during ascending orbits has higher accuracy than during descending orbits, while for the Mie channel, a large bias was obtained during ascending orbit. Vertically, the Mie channel was found to be more capable of detecting winds within the PBL, suggesting a larger impact of Mie winds in data assimilation at these heights. In addition, both difference statistics and triple collocation analysis showed that Mie-cloudy winds are more precise than Rayleigh-clear winds. Moreover, triple collocation analysis showed that the NWP winds are most precise in representing Aeolus measurement scales, followed by WPR measurements, and Aeolus observations have the largest errors for both Rayleigh and Mie comparisons. Overall, the evidence from this study demonstrates that the space-borne lidar is able to detect winds with sufficient accuracy, which implies the 
370 potential benefit of Aeolus winds for data assimilation in numerical weather prediction, feeding different applications such as aeroplane route optimisation or wind energy prediction.

\section{Appendix A:}

The Mie-cloudy winds from 2B11 was corrected following Marseille et al. (2022). The corrected Mie-cloudy winds were

375 sampled along the same profiles and range bins as the original 2B11 data and were extracted for further validation. The employed method is the same as for the original 2B11 Mie-cloudy winds.

After filtering out the outliers, there are 227 match-ups for analysis. Overall, the results from inter-comparison analysis are almost the same as the original Mie-cloudy winds with bias and scaled MAD becoming slightly smaller for all data (Fig. A1).

380 However, for ascending orbit, the scaled MAD increased by $0.28 \mathrm{~m} \mathrm{~s}^{-1}$. This may be caused by the low data quality over complex terrain at East Sale and Cairns. For descending orbit, both bias and scaled MAD increased somewhat, but not significant.

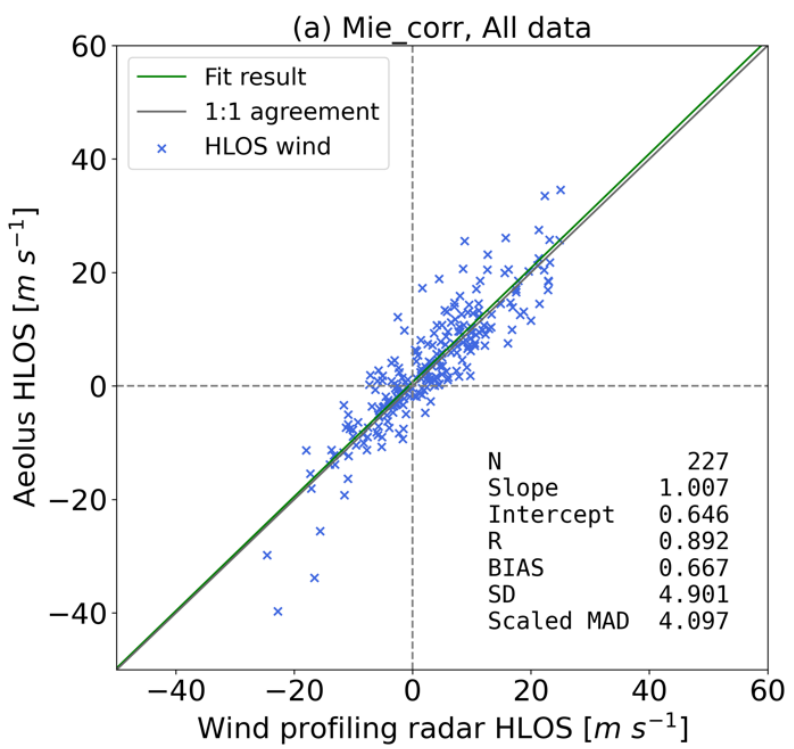


(b) Mie_corr, ascending
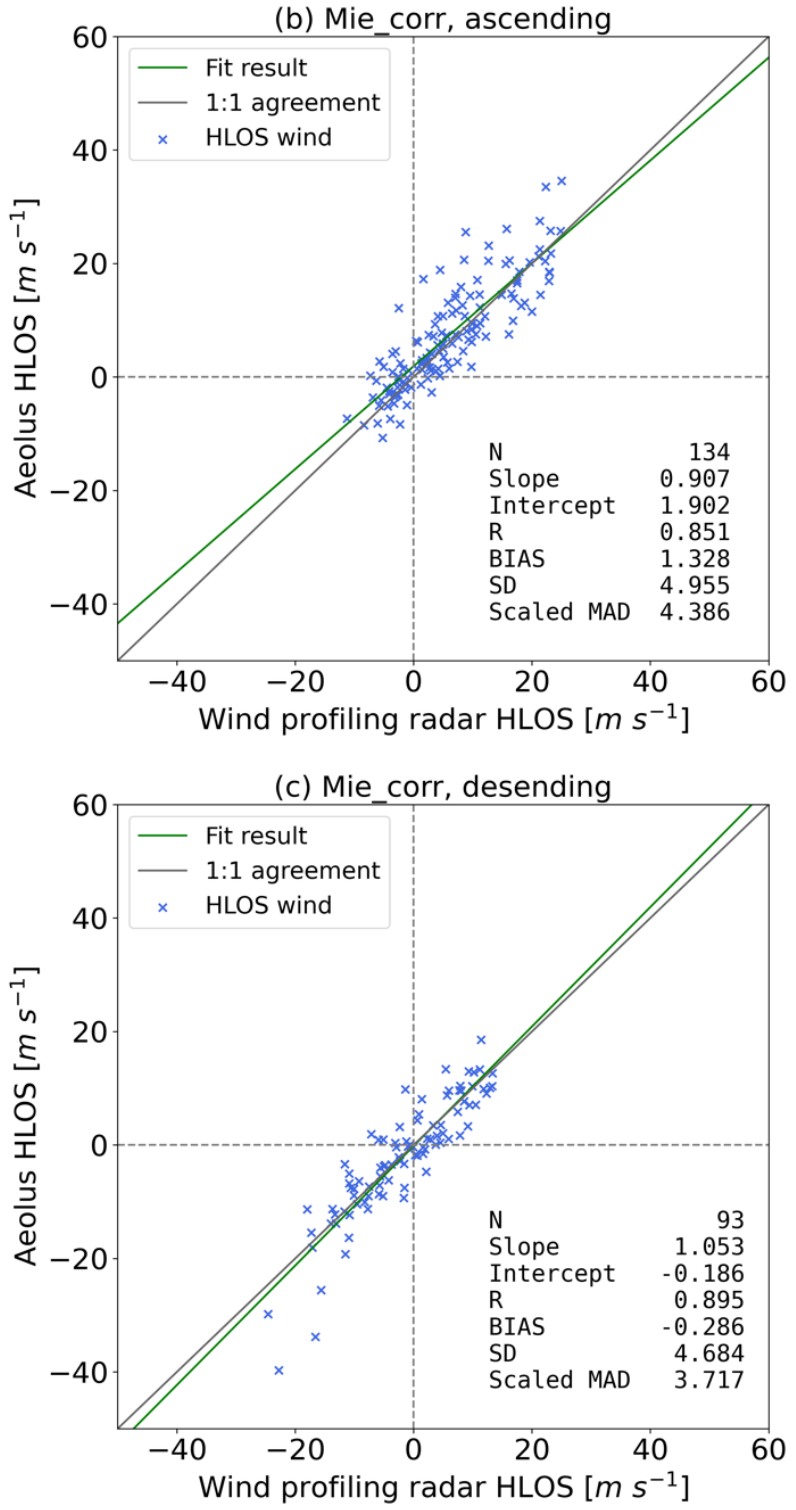

Fig. A1: Scatter plots of corrected Mie-cloudy winds against WPR HLOS winds for all data, ascending orbits and descending orbits. Green and grey lines indicate the fitted regression result and 1:1 agreement, respectively.

Regarding the wind difference as a function of height, some improvements in accuracy and precision can be found mainly below $10,000 \mathrm{~m}$. In particular, for data from all orbits, the random error below 3,000 m reduced by at least $1 \mathrm{~m} \mathrm{~s}^{-1}$, which is in line with the fact that most of the corrected Mie winds are from lower wind speed range. 
(a) All data
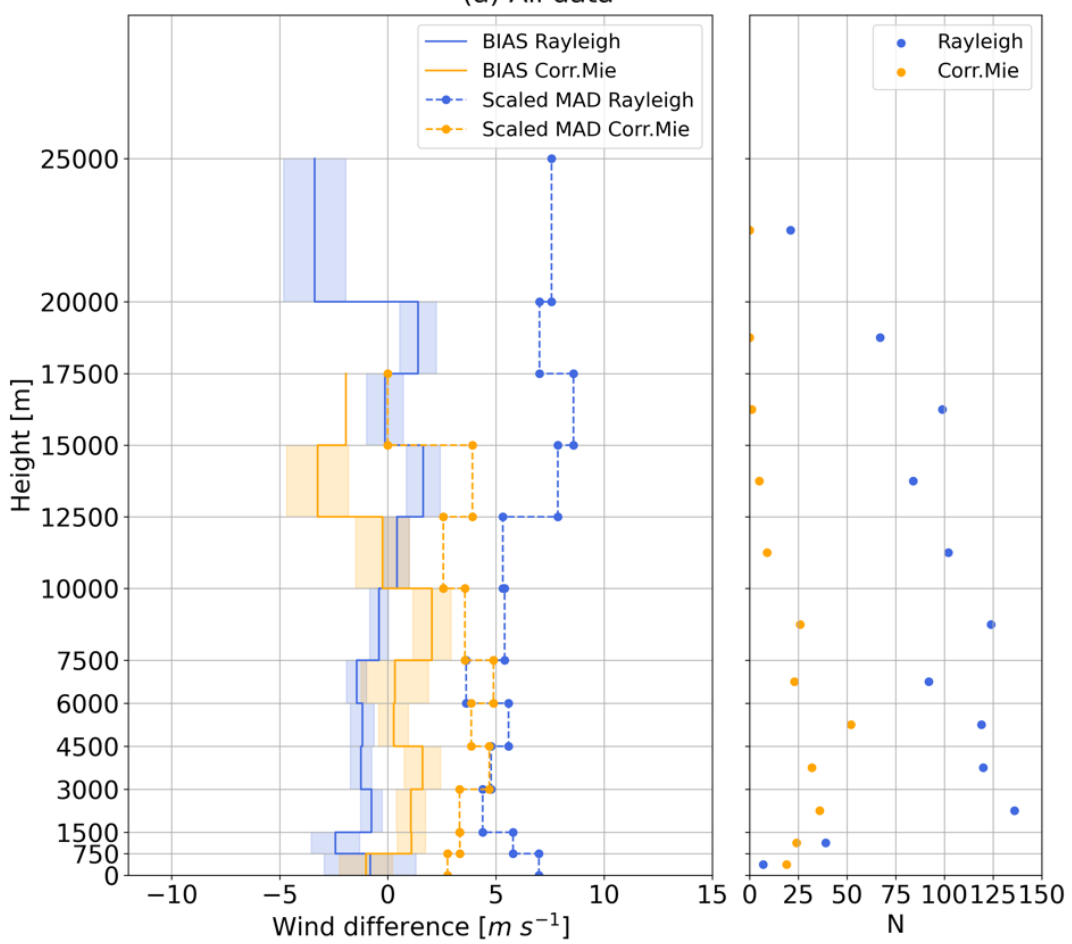

(b) Ascending
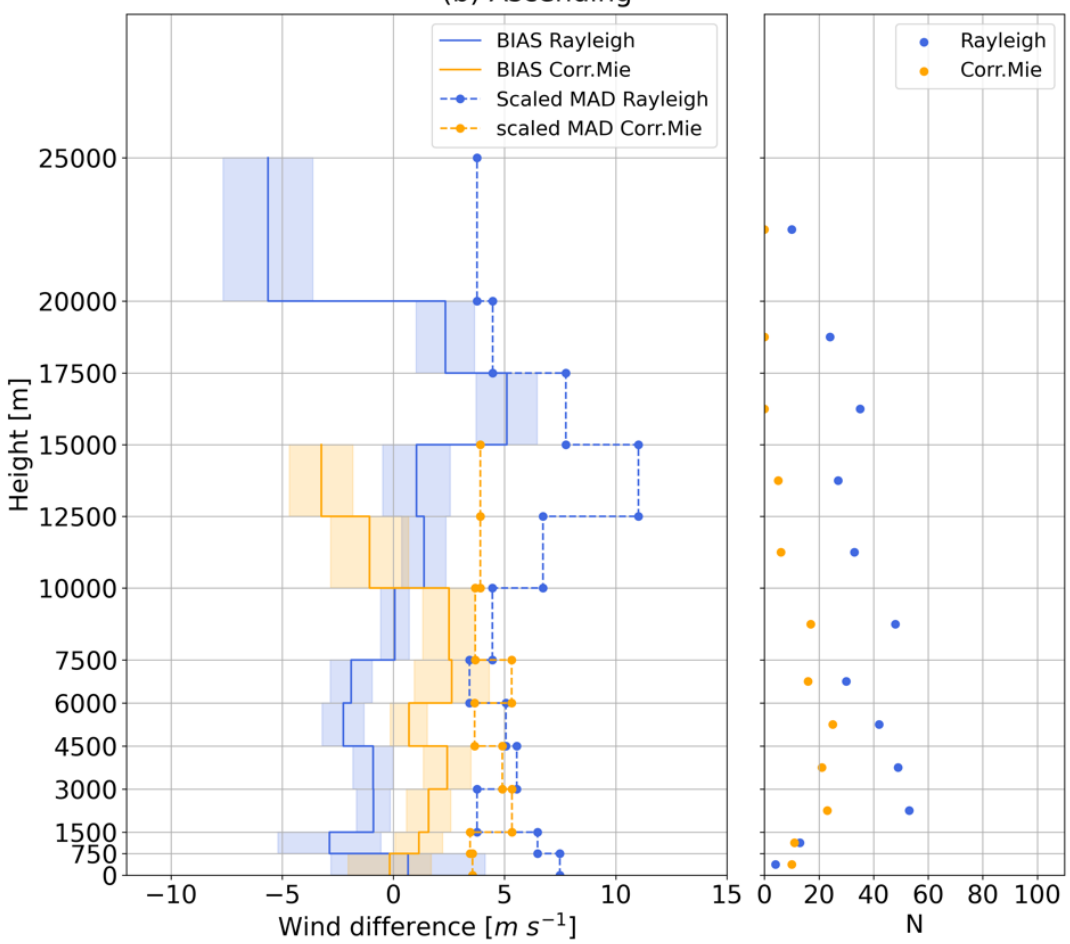
(c) Descending

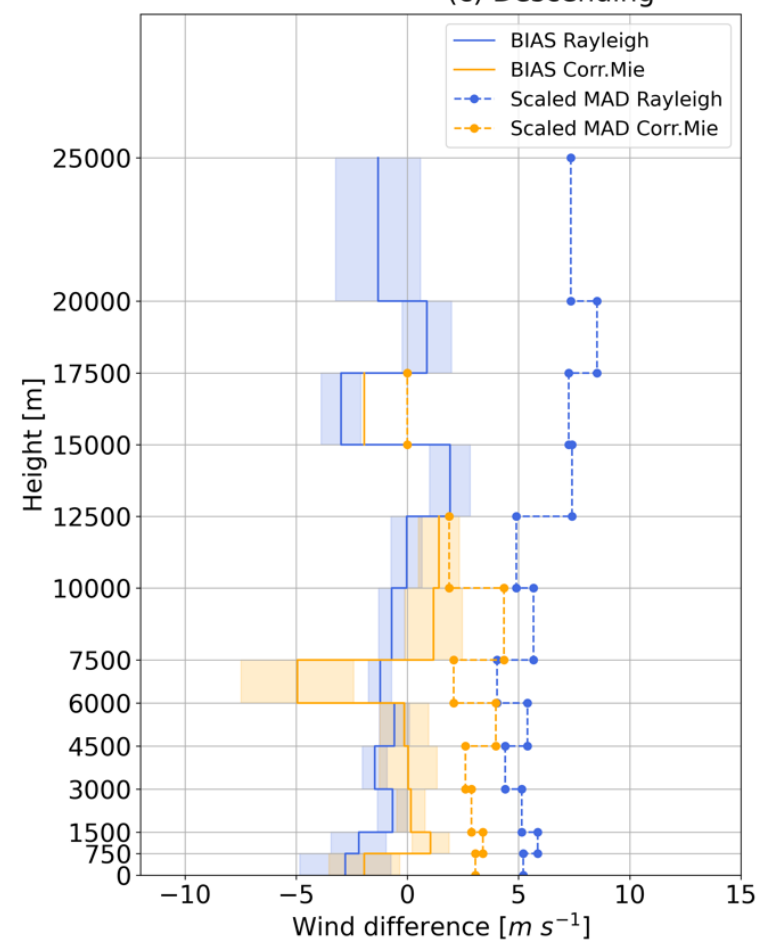

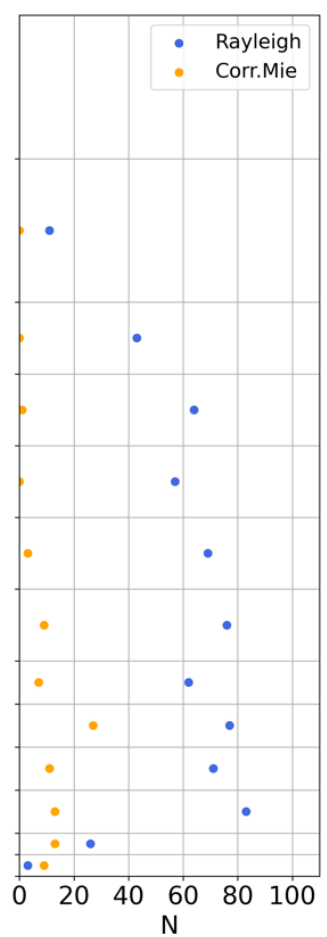

Fig. A2: Wind difference (Aeolus-WPR) with height for (a) all data, (b) ascending orbits and (c) descending orbits. Left: Mean bias and scaled MAD of wind difference as a function of height with shading area representing the uncertainty. Right: the number of available match-ups at each height. Blue and orange colours indicate the Rayleigh-clear and corrected Mie-cloudy winds, respectively.

The results from triple collocation analysis indicate that the correction can reduce the random error of Mie-cloudy winds to some extent but there is some uncertainty due to the limited number of collocated samples. The calibration coefficients are almost comparable with the results based on original 2B11 winds.

Table A1: Error standard deviation of three different systems $\left(\mathrm{m} \mathrm{s}^{-1}\right)$

\begin{tabular}{ccccc}
\hline & 1: WPR & 2: Aeolus L2B & 3: AUX_MET & N \\
\hline $\begin{array}{c}\text { Corrected } \\
\text { Mie-cloudy }\end{array}$ & 3.00 & 3.34 & 1.63 & 227 \\
\hline
\end{tabular}

Table A2: Calibration coefficients of Aeolus L2B and NWP winds

\begin{tabular}{ccccccc}
\hline & \multicolumn{4}{c}{ 2: Aeolus L2B } & \multicolumn{3}{c}{ 3: NWP } \\
\cline { 2 - 7 } & $\mathbf{a 2}$ & $\mathbf{b 2}$ & $\mathbf{H L O S}$ & $\mathbf{a 3}$ & $\mathbf{b 3}$ & HLOS $_{\mathbf{3}}^{*}$ \\
\hline $\begin{array}{c}\text { Corrected } \\
\text { Mie-cloudy }\end{array}$ & 0.337 & 1.115 & 0.897 HLOS $2-0.302$ & -0.031 & 1.129 & 0.886 HLOS3 +0.027 \\
\hline
\end{tabular}


405 The results based on corrected Mie-cloudy winds suggest that the non-linearity bias correction has a potential to reduce the random errors especially for the lower heights, which needs to be further demonstrated by enlarging the data samples or extending the study period.

Data availability. Aeolus Level-2B11 wind product is available at ESA Aeolus Online Dissemination System (http://aeolus410 ds.eo.esa.int/oads/access/, last access: 5 January 2022, ESA, 2021). The wind profiling radar measurements can be obtained from CEDA Archive (https://catalogue.ceda.ac.uk/uuid/9e22544a66ba7aa902ae431bled609d6, last access: 18 December 2021, Met Office, 2008). Aeolus AUX MET files were created by the ECMWF centre and provided by the Royal Netherlands Meteorological Institute (KNMI). Earth relief data were accessed through PyGMT (Wessel et al., 2019; GEBCO Compilation Group, 2021; Sandwell et al., 2021; Uieda et al., 2021). conducted the Mie winds correction. HZ performed the data analysis and drafted the manuscript. AS, GM, CH and IK discussed the validation methods and helped interpreted the research findings. HZ revised the manuscript critically with the help from all co-authors.

Competing interests. Some authors are members of the editorial board of journal Atmospheric Measurement Techniques. The peer-review process was guided by an independent editor, and the authors have also no other competing interests to declare.

Acknowledgements. This study is a part of the $\mathrm{PhD}$ project Aeolus Satellite Lidar for Wind Mapping that is a sub-project of the Innovation

420 Training Network Marie Skłodowska-Curie Actions: Lidar Knowledge Europe (LIKE) supported by the European Union Horizon 2020 (Grant number: 858358). The authors thank ESA Aeolus Online Dissemination System (http://aeolus-ds.eo.esa.int/oads/access/) for access to Aeolus Level-2B baseline 11 near real time HLOS winds. We also acknowledge the Australian Government Bureau of Meteorology for operating the WPR network over Australia and the CEDA for archiving and providing the WPR measurements. The authors are very thankful to KNMI for access to the AUX_MET data files and for being the secondment host institution. Our appreciation also goes to Michael Rennie for the information of NWP model equivalents.

Financial support. This research is a part of the PhD project Aeolus Satellite Lidar for Wind Mapping that is a sub-project of the Innovation Training Network Marie Skłodowska-Curie Actions: Lidar Knowledge Europe (LIKE) supported by the European Union Horizon 2020 (Grant number: 858358).

Review statement. This paper was edited by XXX and reviewed by two anonymous referees.

\section{References}

A Guide to Aeolus Range Bin Settings: https://earth.esa.int/eogateway/news/a-guide-to-aeolus-range-bin-settings, last access: 18 February 2022.

Baars, H., Herzog, A., Heese, B., Ohneiser, K., Hanbuch, K., Hofer, J., Yin, Z., Engelmann, R., and Wandinger, U.: Validation of Aeolus wind products above the Atlantic Ocean, Atmos. Meas. Tech., 13, 6007-6024, https://doi.org/10.5194/amt-13-6007$2020,2020$.

Banyard, T. P., Wright, C. J., Hindley, N. P., Halloran, G., Krisch, I., Kaifler, B., and Hoffmann, L.: Atmospheric Gravity Waves in Aeolus Wind Lidar Observations, Geophys. Res. Lett., 48, https://doi.org/10.1029/2021GL092756, 2021.

Belova, E., Kirkwood, S., Voelger, P., Chatterjee, S., Satheesan, K., Hagelin, S., Lindskog, M., and Körnich, H.: Validation of Aeolus winds using ground-based radars in Antarctica and in northern Sweden, Atmos. Meas. Tech., 14, 5415-5428, https://doi.org/10.5194/amt-14-5415-2021, 2021. 
Caires, S.: Validation of ocean wind and wave data using triple collocation, J. Geophys. Res., 108, 3098, https://doi.org/10.1029/2002JC001491, 2003.

Calvert, J. G.: Glossary of atmospheric chemistry terms (Recommendations 1990), Pure Appl. Chem., 62, 2167-2219, https://doi.org/10.1351/pac199062112167, 1990.

445 Chen, S., Cao, R., Xie, Y., Zhang, Y., Tan, W., Chen, H., Guo, P., and Zhao, P.: Study of the seasonal variation in Aeolus wind product performance over China using ERA5 and radiosonde data, Atmos. Chem. Phys., 21, 11489-11504, https://doi.org/10.5194/acp-21-11489-2021, 2021.

de Kloe, J., Stoffelen, A., Tan, D., Andersson, E., Rennie, M., Dabas, A., Poli, P., and Huber, D.: Aeolus Data Innovation Science Cluster DISC ADM-Aeolus Level-2B/2C Processor Input/Output Data Definitions Interface Control Document, https:/earth.esa.int/eogateway/documents/20142/37627/Aeolus-L2B-2C-Input-Output-DD-ICD.pdf, 2021.

Dolman, B., Reid, I., and Kane, T.: The Australian Wind Profiler Network, WMO Technical Conference on Meteorological and Environmental Instruments and Methods of Observation (TECO-2016), Madrid, Spain, 2016.

Dolman, B. K., Reid, I. M., and Tingwell, C.: Stratospheric tropospheric wind profiling radars in the Australian network, Earth Planets Space, 70, 170, https://doi.org/10.1186/s40623-018-0944-z, 2018.

ESA: ESA Aeolus Online Dissemination, ESA [data set], https://aeolus-ds.eo.esa.int/oads/access/, 2021.

GEBCO Compilation Group: GEBCO 2021 Grid, British Oceanographic Data Centre (BODC) [data set], https://www.gebco.net/data_and_products/gridded_bathymetry_data/, 2021.

Guo, J., Liu, B., Gong, W., Shi, L., Zhang, Y., Ma, Y., Zhang, J., Chen, T., Bai, K., Stoffelen, A., de Leeuw, G., and Xu, X.: Technical note: First comparison of wind observations from ESA's satellite mission Aeolus and ground-based radar wind profiler network of China, Atmos. Chem. Phys., 21, 2945-2958, https://doi.org/10.5194/acp-21-2945-2021, 2021.

Houchi, K., Stoffelen, A., Marseille, G. J., and De Kloe, J.: Comparison of wind and wind shear climatologies derived from high-resolution radiosondes and the ECMWF model, J. Geophys. Res., 115, D221231-15, https://doi.org/10.1029/2009JD013196, 2010.

Ingmann, P. and Straume, A. G.: ADM-Aeolus Mission Requirements Document, https://esamultimedia.esa.int/docs/EarthObservation/ADM-Aeolus_MRD.pdf, 2016.

Iwai, H., Aoki, M., Oshiro, M., and Ishii, S.: Validation of Aeolus Level 2B wind products using wind profilers, ground-based Doppler wind lidars, and radiosondes in Japan, Atmos. Meas. Tech., 14, 7255-7275, https://doi.org/10.5194/amt-14-72552021, 2021.

Krisch, I. and Aeolus DISC: Data quality of Aeolus wind measurements, EGU General Assembly 2020, Online, EGU20209471, https://doi.org/10.5194/egusphere-egu2020-9471, 2020.

Lin, W., Portabella, M., Stoffelen, A., Vogelzang, J., and Verhoef, A.: On mesoscale analysis and ASCAT ambiguity removal, Q.J.R. Meteorol. Soc., 142, 1745-1756, https://doi.org/10.1002/qj.2770, 2016.

Marseille, G., Kloe, J., Marksteiner, U., Reitebuch, O., Rennie, M., and Haan, S.: NWP calibration applied to Aeolus Mie channel winds, Q.J.R. Meteorol. Soc., 1-15, https://doi.org/10.1002/qj.4244, 2022. 
475 Martin, A., Weissmann, M., Reitebuch, O., Rennie, M., Geiß, A., and Cress, A.: Validation of Aeolus winds using radiosonde observations and numerical weather prediction model equivalents, Atmos. Meas. Tech., 14, 2167-2183, https://doi.org/10.5194/amt-14-2167-2021, 2021.

Met Office: Wind Profiler Observations, Part of the Met Office MetDB System, NCAS British Atmospheric Data Centre [data set], https://catalogue.ceda.ac.uk/uuid/9e22544a66ba7aa902ae431b1ed609d6, 2008.

480 Portabella, M. and Stoffelen, A.: On Scatterometer Ocean Stress, J. Atmos. Oceanic Technol., 26, 368-382, https://doi.org/10.1175/2008JTECHO578.1, 2009.

Rennie, M.: About access to Aeolus AUX_MET data, 2021.

Rennie, M., Tan, D., Andersson, E., Poli, P., Dabas, A., De Kloe, J., Marseille, G.-J., and Stoffelen, A.: Aeolus Level-2B Algorithm Theoretical Basis Document (Mathematical Description of the Aeolus L2B Processor), https://earth.esa.int/pi/esa?type=file\&table=aotarget\&cmd=image\&alias=Aeolus_L2B_Algorithm_TBD, 2020.

Rennie, M. P. and Isaksen, L.: The NWP impact of Aeolus at ECMWF, https://www.ecmwf.int/node/19538, 2020.

Rennie, M. P., Isaksen, L., Weiler, F., Kloe, J., Kanitz, T., and Reitebuch, O.: The impact of Aeolus wind retrievals on ECMWF global weather forecasts, Q. J. R. Meteorol. Soc., 147, 3555-3586, https://doi.org/10.1002/qj.4142, 2021.

Ribal, A. and Young, I. R.: Global Calibration and Error Estimation of Altimeter, Scatterometer, and Radiometer Wind Speed

Using Triple Collocation, Remote Sens., 12, 1997, https://doi.org/10.3390/rs12121997, 2020.

Ruppert, D.: Statistics and Data Analysis for Financial Engineering, 1st ed., Springer, New York, NY, USA, 2011.

Sandwell, D. T., Goff, J. A., Gevorgian, J., Harper, H., Kim, S.-S., Yu, Y., Tozer, B., Wessel, P., and Smith, W. H. F.: Improved Bathymetric Prediction using Geological Information: SYNBATH, Earth Space Sci., 30, https://doi.org/10.1002/essoar.10508279.1, 2021.

Satellites track unusual Saharan dust plume: https://www.esa.int/Applications/Observing_the_Earth/Satellites_track_unusual_Saharan_dust_plume, last access: 28 August 2021.

Skamarock, W. C.: Evaluating Mesoscale NWP Models Using Kinetic Energy Spectra, Mon. Wea. Rev., 132, 3019-3032, https://doi.org/10.1175/MWR2830.1, 2004.

500 Stoffelen, A.: Toward the true near-surface wind speed: Error modeling and calibration using triple collocation, J. Geophys. Res., 103, 7755-7766, https://doi.org/10.1029/97JC03180, 1998.

Stoffelen, A., Vogelzang, J., and Marseille, G.-J.: High-resolution wind data-assimilation guide, https://nwpsaf.eumetsat.int/site/download/documentation/scatterometer/reports/High_Resolution_Wind_Data_Assimilation_Guide_1.3. pdf, 2020.

505 Uieda, L., Tian, D., Leong, W. J., Jones, M., Schlitzer, Toney, L., Grund, M., Yao, J., Magen, Y., Materna, K., Newton, T., Anant, A., Ziebarth, M., Wessel, P., and Quinn, J.: PyGMT: A Python interface for the Generic Mapping Tools, Zenodo, https://doi.org/10.5281/ZENODO.5607255, 2021.

Vallejos-Burgos, F., Coudert, F.-X., and Kaneko, K.: Air separation with graphene mediated by nanowindow-rim concerted motion, Nat. Commun., 9, 1812, https://doi.org/10.1038/s41467-018-04224-6, 2018. 

https://cdn.knmi.nl/system/data_center_publications/files/000/068/914/original/triplecollocation_nwpsaf_tr_kn_021_v1.0.pd f? 1495621500, 2012.

Vogelzang, J., Stoffelen, A., Verhoef, A., and Figa-Saldaña, J.: On the quality of high-resolution scatterometer winds, J. Geophys. Res., 116, C10033, https://doi.org/10.1029/2010JC006640, 2011.

515 Wallace, J. M. and Hobbs, P. V.: Cloud Microphysics, in: Atmospheric Science An Introductory Survey, vol. 92, Elsevier, USA, 2006.

Wessel, P., Luis, J. F., Uieda, L., Scharroo, R., Wobbe, F., Smith, W. H. F., and Tian, D.: The Generic Mapping Tools Version 6, Geochem. Geophys. Geosyst., 20, 5556-5564, https://doi.org/10.1029/2019GC008515, 2019.

World Meteorological Organization (WMO): Proceedings of the 3rd WMO Workshop on The Impact of Various Observing Systems on Numerical Weather Prediction, Alpbach, Austria, 1-324, 2004.

Wu, S., Sun, K., Dai, G., Wang, X., Liu, X., Liu, B., Song, X., Reitebuch, O., Li, R., Yin, J., and Wang, X.: Inter-comparison of wind measurements in the atmospheric boundary layer and the lower troposphere with Aeolus and a ground-based coherent Doppler lidar network over China, Atmos. Meas. Tech., 15, 131-148, https://doi.org/10.5194/amt-15-131-2022, 2022.

Zhang, W., Guo, J., Miao, Y., Liu, H., Zhang, Y., Li, Z., and Zhai, P.: Planetary boundary layer height from CALIOP compared to radiosonde over China, Atmos. Chem. Phys., 16, 9951-9963, https://doi.org/10.5194/acp-16-9951-2016, 2016. 